\title{
LOS CONTEXTOS SOCIALES E INSTITUCIONALES DE UNA ECONOMÍA MONÁSTICA: SANTA MARÍA DE MONTEDERRAMO EN EL SIGLO XIII ${ }^{1}$
}

\author{
Dpt. of Medieval History \\ ST. ANDREWS \\ SCOTLAND
}

ESTHER PASCUA ECHEGARAY

\section{RESUMEN}

La autora se pregunta por las causas de la consolidación y pervivencia de formas institucionales ineficientes desde un punto de vista económico. Se estudia un caso concreto: el monasterio cisterciense de Santa María de Montederramo (Orense) en el siglo XIII para poner en evidencia la existencia de marcos institucionales formales e informales definidores de la acción de unos agentes cuyos intereses se construyeron en el proceso de interacción social, es decir, en contextos socio-culturales determinados y no como fruto de la limitación institucional sobre la naturaleza maximizadora de agentes extemporales. En primer lugar, el artículo presenta las paradojas en los debates clásicos sobre el Císter. Atendiendo a la Regla de la Orden, se acepta que el Císter perseguía varios objetivos: la compactación de las parcelas adquiridas, la tenencia en régimen de propiedad no compartida y la explotación de la tierra con mano de obra propia. A partir del caso elegido se reflexiona sobre la distancia entre los principios teóricos de la Orden y la morfología diversa de los señoríos y sus formas de gestión práctica. Se concluye que los monasterios se convirtieron en aparatos acumuladores de bienes invirtiendo recursos según criterios de reciprocidad, redistribución, identidad y estableciendo redes con las comunidades o con algunos de sus miembros destacados. En este compacto entramado de dinámicas sociales y mentales se fueron configurando sus formas económicas.

${ }^{1}$ Quiero agradecer a Reyna Pastor, Jesús Martínez Izquierdo y Maribel Alfonso Antón el tiempo dedicado a leer y corregir este artículo. Sin su ayuda, nunca habría conseguido afinar mis apreciaciones y orientar el argumento. Los errores, por supuesto, son de mi exclusiva responsabilidad. 


\section{ABSTRACT}

The author searches into the reasons for the perpetuation of inefficient institutions. The monastery of Sta. Maria de Montederramo (Orense, Galicia) in the 13th century lets to underline the existence of formal and informal institutions defining agents' choices whose interests are building up in the process of social interaction. Moreover those interests emerge within socio-cultural context, rather than as the outcome of the institutional constreints over a given nature as profit maximazers. The article reviews the classical debate about the Cister. Given the Rule of the Order it is argued that Cistercians pursued the organization of coherent territorial estates, exclusive property rights over the land and own labour force. Working on the case-study, the gap between the theoretical principle of the Order and the specif management and contractual agreements about land tenancy are considered. The conclusion puts forward that monasteries were devices of accumulation because they developed practices of reciprocity, redistribution and identity within the peasant communities and through the organization of personal and social networks with some of the outstanding members of the local community. In the tied web of social and cultural dynamics, the economic patterns were hammered out.

\section{PRESENTACIÓN DEL DEBATE Y MARCO ANALÍTICO}

En un artículo sobre el Císter es conveniente empezar observando que las múltiples y diversas interpretaciones sobre la Orden no han dado lugar a un debate coherente en torno a la misma. Una razón de ello puede ser que sus participantes no han hablado el mismo lenguaje ni se han preguntado por las mismas cuestiones. Por ello, se hace difícil sistematizar los núcleos de discusión, pero tiene interés hacerlo para desvelar las contradicciones y lagunas explicativas en las que está todavía el tema.

Gran parte de la Historia Social de los años sesenta dedicada a la formación de los señoríos monásticos trabajó con la idea de que los monasterios, incluidos los cistercienses, fueron las principales instituciones en el proceso de feudalización de la Península Ibérica. Su poder señorial e ideológico, derechos jurisdiccionales, privilegios políticos y fuerza militar les permitió servilizar, acumular tierras y rentas y arrollar comunidades de aldea (Gautier Dalche, 1958; García de Cortázar, 1969; Moreta Velayos, 1971; Bonauda, 1970). Por su parte, la corriente dominante de la Historia Económica interesada en las economías monásticas se sintió fascinada por la eficiencia y racionalidad del sistema de explotación cisterciense. Su organización en granjas geográficamente homogéneas, trabajadas directamente 
con mano de obra conversa, centros de roturación de nuevas tierras y de implantación de las técnicas más innovadoras con fines comerciales parecía la encarnación del cálculo maximizador de beneficios resultado de la dinámica recién nacida de los mercados y los precios. Los aspectos sustantivos que explicaban algunas de las características más emblemáticas de la ineficiencia de estas organizaciones quedaron en segundo lugar (Moulin, 1978; Comba, 1983; Chiappa, 1985; Higounet, 1957).

Investigaciones orientadas al análisis regional y local han ido poniendo en cuestión ambas interpretaciones al hacer notar la diversidad de los dominios cistercienses en las distintas áreas. Cruzando las perspectiva anteriores, la paradoja resulta ser doble: si el Císter era una organización todopoderosa, capaz de poner en marcha las formas más eficientes de explotación - como defiende cierta Historia Social y Económica - no se entiende que tuviera diferentes formas de gestión en unas zonas y otras, en unos monasterios y otros, en unos períodos y otros. Habría desarrollado un método uniforme de organización frente a la débil oposición de derrotadas comunidades campesinas. Pero sabemos que esto no fue así. La teórica explotación directa mediante el trabajo de monjes y conversos no fue nunca tal y la morfología de los señoríos cistercienses se fue configurando en un mar de privilegios jurisdiccionales, comunidades de caballeros y campesinos y rentas de diversas clases.

Del campo de la Historia de la Iglesia procedieron algunas de las explicaciones a lo que por entonces empezó a conocerse como la tesis de la progresiva «decadencia de la Orden». El Císter, según sus autores más representativos, sufrió un proceso de decadencia moral y espiritual que se reflejó en una progresiva traición a la Regla original (Lekai, 1957; Mahn, 1910; Valous, 1935; Pérez de Urbel, 1933; Orlandis, 1971; Pérez Embid, 1986, y Álvarez Palenzuela, 1978). Esta hipótesis como marco analítico del Císter está lastrada por dos objeciones. Una es de tipo empírico, pues desde su fundación los monasterios cistercienses adquirieron bienes y desarrollaron prácticas no acordes con las disposiciones del Capítulo General, si bien con variaciones en unas zonas y otras. La segunda es teórica, pues la cuestión de la decadencia moral no ofrece ninguna explicación sobre la causa del desarrollo de un tipo de dominio u otro.

La historiografía reciente ha ido desmontando uno a uno todos los mitos de la cosmología cisterciense. Se ha afirmado que los asentamientos no fueron marginales, ni innovadores en la implantación de tecnología, ni pioneros en roturación, ni excepcionales en el reclutamiento de la mano de obra (Alfonso Antón, 1986; McCrank, 1983). El Císter se adaptó desde 
un principio a las estructuras de producción de la sociedad feudal y tuvo formas variadas de adquisición y gestión. Éstas dependieron de las limitaciones que le impusieron ciertos sectores de las comunidades locales, como los caballeros o milites (Bouchard, 1986; Barnes, 1984; Berman, 1986, 1987; Wardrop, 1987). Su gran éxito económico se explica por la combinación de una cuidadosa política de compras y una incesante reordenación de parcelas que llevaban tiempo puestas en cultivo (Berman, 1986), además de por la organización de un sistema de trashumancia que implicó un aumento de la ratio de los animales por hectárea de cereal durante un período de crecimiento de la demanda urbana de cuero, carne, pergamino $\mathrm{y}$ otros productos animales. Por último, el favor regio y pontificio, que se reflejó en una extendida exención de impuestos, vino a completar su imparable disponibilidad de capital reinvertido en tierra.

La paradoja antes señalada vuelve a hacer sonar sus ecos. Por un lado, queda sin explicar la oscura causa de la «traición» a la Regla que desencadenó el éxito económico cisterciense más allá de la mera asunción de que los monjes sucumbieron a las tentaciones del mercado. Por otro, se hace todavía más difícil entender la distancia entre teoría y práctica en una Orden cuyos principios abogaron por la clarificación de los derechos de propiedad y el control del proceso de producción, mientras su actuación perpetuó marcos institucionales supuestamente ineficientes desde un punto de vista netamente económico: aceptación de bienes fundiarios compartidos, arrendamientos y poderes jurisdiccionales.

El diseño teórico derivado del Exordium Parvum y la Carta Caritatis aspiraba a la organización de una forma de producción y distribución independiente de las comunidades aldeanas mediante conversos (campesinado residente en las dependencias del monasterio que recibía votos menores, dedicado en exclusiva al trabajo manual a cambio de su sustento) y granjas (centros de explotación directa gestionados por monjes o conversos, a una distancia máxima de un día de viaje del monasterio). Los monasterios debían situarse en lugares yermos, lejos de jurisdicciones ajenas, evitar el báculo episcopal y no aceptar ningún bien que no fuera de propiedad exclusiva. Sus monjes estaban obligados a trabajar la tierra o ayudarse con los antes mencionados conversi. A diferencia de lo que ocurría en los monasterios benedictinos, quedaba prohibida toda adquisición de numerario derivado de la atención a peregrinos, diezmos, rentas jurisdiccionales o prés$\operatorname{tamos}^{2}$.

\footnotetext{
${ }^{2}$ Canivez (1933), vol. I.
} 
$\mathrm{El}$ intento puede interpretarse como una ofensiva contra los lazos de parentesco, vecindad o dependencia, seña inconfundible en el nivel local de la ligazón entre bienes, productores y señores, para conformar una organización, sea la Orden en su conjunto o un monasterio, con mucha más autonomía patrimonial ${ }^{3}$. Este artículo pretende llamar la atención sobre la causa de la acomodación de los monasterios cistercienses a los contextos socio-económicos regionales. Su actuación no se interpretará como un resultado inintencional de actores con una racionalidad maximizadora, constreñidos por contextos sociales e institucionales adversos, sino como el resultado de una actuación cuyas intenciones económicas se conformaron en el proceso de interacción social con otros actores (Pizzorno, 1987, 1989).

\section{DESCRIPCIÓN DE UN MONASTERIO Y SU ENTORNO}

La base empírica de este artículo es el monasterio cisterciense de Santa María de Montederramo, situado en la actual provincia y diócesis de Orense, una zona de elevada altitud media y todavía hoy una región de baja densidad demográfica. El trabajo se ha realizado sobre 525 documentos inéditos de los siglos XII y XII ${ }^{4}$. Como se puede observar en el gráfico número 1 , las formas más frecuentes de transacciones que tenemos en esta documentación son en cierto modo particulares, si bien pueden plegarse a la clásica denominación de precaria: precaria data o entrega de tierras a campesinos a cambio del pago de renta (47 por 100), precaria oblata o donaciones que el monasterio devolvía a los donantes a cambio del pago de renta (10 por 100) y precaria remuneratoria o cambio en el que el cultivador entregaba su tierra al monasterio y recibía otra a cambio, quedándose con ambas durante su vida, pagando renta y liberando las dos a su muerte $(7,3 \text { por } 100)^{5}$. Todas ellas son precedentes de las diversas

${ }^{3}$ A pesar de la innovación que pueda parecer, no se trató de un intento aislado. Por un lado, comparte tendencia con la fuerte reacción que, en general, protagonizó la nobleza del siglo xII frente a los problemas de dominación de las comunidades campesinas y de la apropiación creciente de su excedente (Brenner, 1996, 1988). Por otro, es una de las manifestaciones del proceso de institucionalización que inició la Iglesia a finales del siglo XI, tras la Reforma Gregoriana, y cuya batalla central, junto a la simonía, fue el nicolaísmo: la creación de un cuerpo de clérigos sin esposa ni hijos, sin entorno social.

4 El director del Instituto de Filología de la Lingua Galega de Santiago de Compostela, D. Ramón Lorenzo, ha tenido la amabilidad de ofrecernos los documentos transcritos de la edición que está ultimando de toda la documentacion del monasterio recogida de diversos archivos, si bien especialmente del Archivo de la Catedral de Orense.

"García de Valdeavellano las denominó «precaria remuneratoria», el antecedente del 


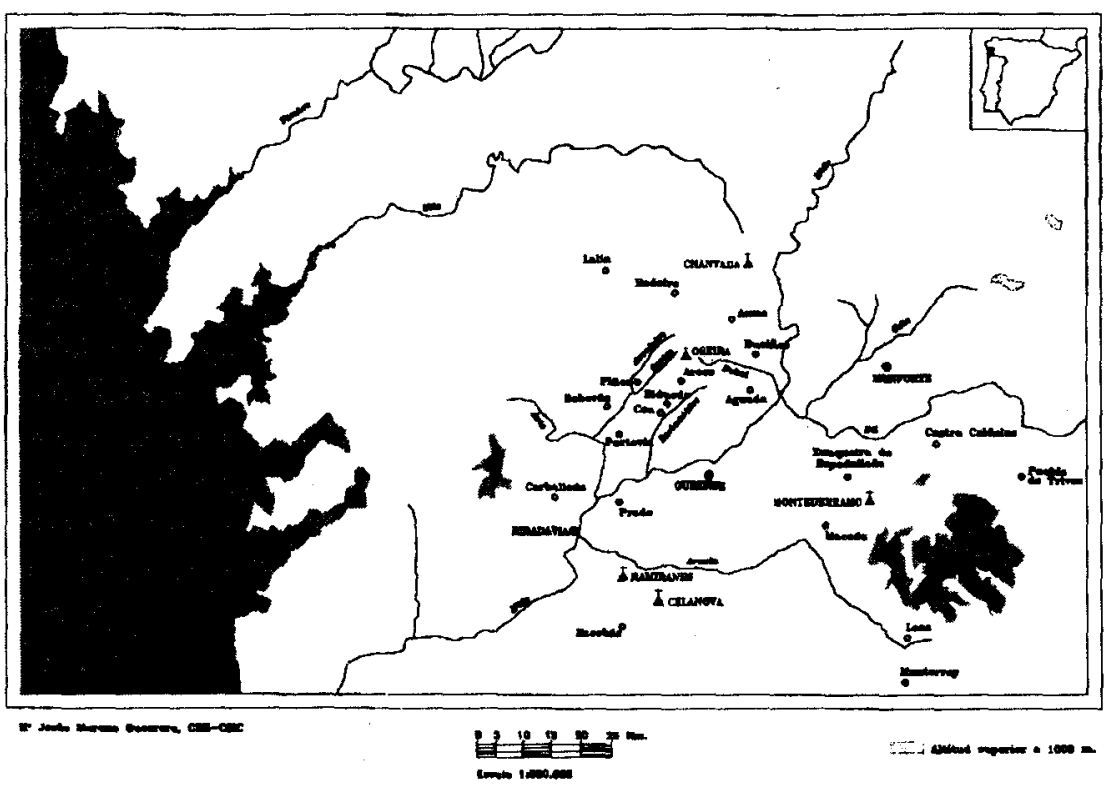

formas del régimen foral gallego. La precaria data que aparece en Montederramo es muy particular, pues el cultivador no recibía cualquier tierra, sino la que él mismo había vendido al monasterio por un precio, manteniendo la capacidad de volver a venderla si lo deseaba o lo necesitaba y la obligación de entregarla al monasterio a su muerte.

La precaria remuneratoria, una combinación de las dos anteriores, arroja magníficos ejemplos que ilustran los mecanismos por los que el monasterio convertía propiedad dominical de laicos en su propio dominio: en 1275 los monjes aforan a una pareja un casal (unidad compleja de explotación, de gran tamaño, que incluía la producción de cultivos diversos) y otras heredades en la localidad de Cristina. A cambio reciben toda la heredad que la pareja tiene en este mismo lugar. Los otorgantes disfrutan del conjunto de propiedades para explotarlas hasta la muerte de su hijo, período al final del cual los bienes pasarían a la jurisdicción del cenobio ${ }^{6}$.

«prestimonio» típico de Castilla y León, una combinación de la precaria data y oblata (1993, pp. 249-50). Autores centrados en la realidad gallega las califican como «precaria conmutativa» (Marino, 1983, pp. 173-177).

- Doc. 327; también Doc. 185, 1257. En 1272 y 1275 Pedro Campesino concede todo lo que tiene en el monte y la villa de Escuadro a cambio de mantener la posesión de 


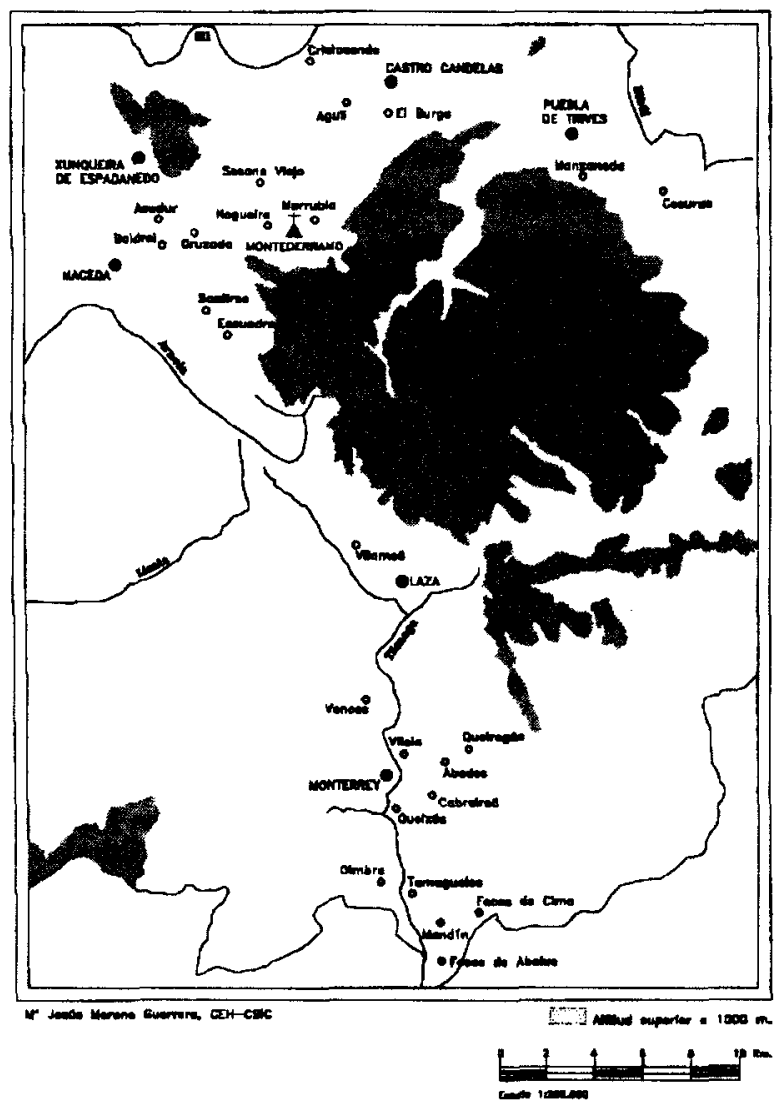

En cierta medida el monasterio de Santa María de Montederramo respondía al modelo económico clásico del Císter de granjas diseminadas que combinan la producción cerealera, silvo-pastoril y vitícola, orientando productos como el centeno, el queso, la leche y la mantequilla al consumo en el monasterio y productos derivados de la cabaña (carne y lana principalmente), trigo y vino, a la venta en los mercados regionales. Pero la localización de las granjas de Montederramo denota la poca relevancia de uno de los grandes mitos de la Orden: que los monasterios se situaran en zonas alejadas o poco habitadas, argumento por el que se les ha erigido en artífices de la roturación y la expansión de los cultivos en la Plena

ambos. Al final de sus dias el monasterio recibiría, además, lo que éste tenía en Calvelo y Cabanellas (Doc. 317). 
Edad Media ${ }^{7}$. Montederramo, es cierto, estaba en una zona de monte, pero la ofensiva de compras se dirigió a zonas de valle, de viña, fértiles, habitadas y cultivadas, algunas muy cercanas a grandes ciudades ${ }^{8}$.

$\mathrm{El}$ patrimonio fundiario de Montederramo, como en el caso de todos los otros centros de la Orden durante el siglo XII, se aquilató gracias a las grandes donaciones regias en torno a cotos y casales aislados, otorgados por el rey Alfonso VII de Castilla y León como espacios dotados de inmunidad fiscal con derechos señoriales sobre los habitantes de la zona, es decir, con derechos de renta, posiblemente en especies, y prestaciones de trabajo 9 . Las primeras donaciones regias configuraron un coto alrededor del monasterio, otro en la montaña y dos a orillas del Sil ${ }^{10}$. Este proceso explica que el coto tuviera una homogeneidad geográfica sólo relativa con derechos de carácter dominical y señorial, con jurisdicción sobre tierra y hombres, quedando excluidos derechos eclesiásticos como el diezmo. Desde la segunda mitad de siglo comenzaron a tener más peso las donaciones de particulares, si bien nunca fueron muy abundantes.

${ }^{7}$ Una bula del papa Alejandro III registra las numerosas granjas que regentó Montederramo. En Tierra de Quiroga: Seoane de Trives y Vilachá del Salvador; en Costa de Sadur: San Tirso; en Tioira: Santa Marta; en Chandreja del Sil: San Martín de Manzaneda y San Cipriano de Peña; en Trives: Cerdeira y Santa María de Cova. Algunas fueron resultado de la transformación de iglesias o parroquias: San Miguel de Ribas de Sil, San Martín de Piñeira, San Adrián de Ribas de Sil, Santa María de Castro de Rey y Seoane Vello. Otras estuvieron dedicadas exclusivamente a la cría de ganado y la producción de queso y leche, como los prioratos de Queija y Verín (Cacharrón, 1988, pp. 50-51). En la bula se enumera, además, la posesión de heredades en Asadur, Celeirón, Parada, Baldrey, Junquera de Espadañedo, Sarreaus, Santa Eulalia de Escuadro, Sistín, Montoedo, Cristosende, Lampaza, Castrelo, Queija, Retorta, Monterrey, Verín, Penapetada. Y casales en: Tabeda, Candedo, Tabouazas, Pradoalvar y Santa Cruz (Doc. 23, 1163, y Cacharrón, 1988, pp. 66-67). En la segunda mitad del siglo XII se documenta la granja de Tamaganos y el cillero de Queiruganes (Doc. 229).

${ }^{8}$ Esta política se dirigió: a las orillas del Sil en torno a Quiroga, Trives y Castro Caldelas; alrededor de Manzaneda-Seoane y en la complicada región alrededor de Monterrey (Tamaganos, Nocedo, Abedes y Queiruganes). Pero, sobre todo, se persiguió acaparar derechos de monte en la zona de altura media de Costa-Santirso, Escuadro y Manzaneda.

9 En 1155 monjes de Claraval se asentaron en un cenobio de filiación benedictina localizado en Seoane el Viejo. En 1163 la bula antes mencionada del papa Alejandro III confirma por primera vez la filiación cisterciense de Santa María de Montederramo (Cocheril, 1966, p. 344). El monasterio recibió, por tanto, parte de sus bienes de un núcleo anterior. En las confirmaciones regias posteriores de los privilegios de coto que recibió el monasterio se especifica que no le sean cobrados impuestos o rentas por circular sus hombres por su coto o por construir casas o por vender o por lo que produjera en él (Doc. 469).

${ }^{10}$ Según la bula del papa Alejandro III, los cotos eran: uno más próximo al monasterio con seis granjas (San Ciprián de Peña, San Adrián, San Miguel, Santa Marta, Piñeira y Salcedo); otro en Pradomanes, al noreste, con nueve granjas diseminadas por toda la geografía (San Juan el Viejo, Praducelo, Pelagiones, Cerdera, Lanza, Baronceli, Santa Colomba, San Juan de Cova y Buazo. Doc. 23). 
GRÁFICO 1.

Distribución del tipo de transacciones en Santa María de Montederramo (Siglo XIII) (\%)

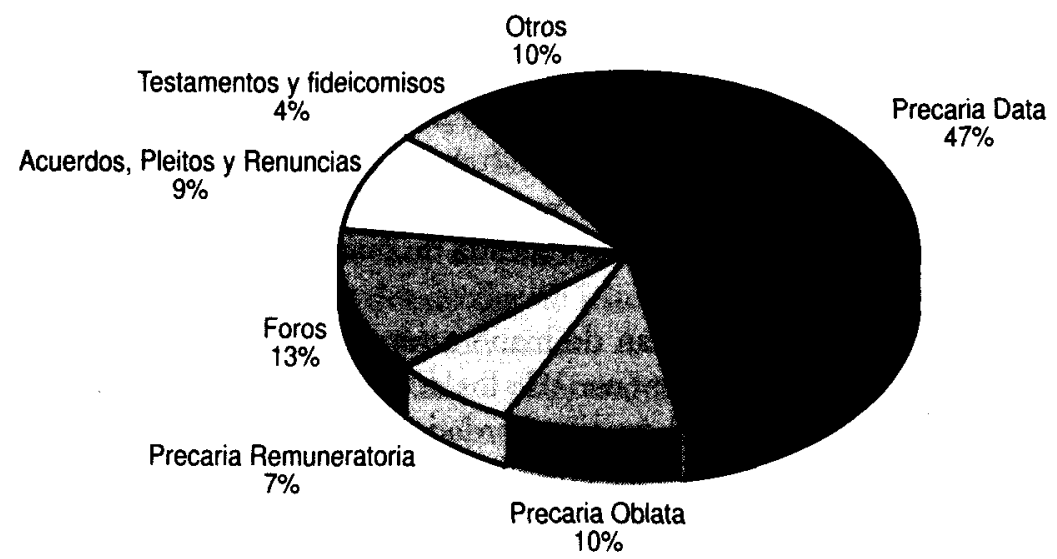

Finalizada la fase de primeras donaciones, como el resto de monasterios cistercienses, Montederramo inició la compra de pequeñas propiedades a distintos posesores, incluyendo desde el principio propietarios de diezmos e iglesias. No es casualidad que la compra sea la transacción que más claramente persigue un ejercicio del derecho de propiedad absoluto sobre el bien adquirido si la comparamos con otras modalidades como donaciones, cambios o préstamos, en el sentido de excluir posibles reclamaciones de parientes y herederos.

La profesora Berman ha descrito para la región del Midí francés las dos estrategias que rigieron la actuación económica de toda la Orden. Ella denomina «compactación horizontal» al intento del Císter de comprar la propiedad dominical de nuevas tierras adyacentes a otras que ya poseían y «compactación vertical» a la restitución de la propiedad, reduciendo el número de personas, desde señores a campesinos, con derechos a reclamar las tierras (Berman 1988, pp. 10 y 43).

Varias cláusulas documentales del siglo xII, orientadas a precisar los derechos de propiedad de las partes implicadas en las transacciones, acreditan el interés del monasterio en cercenar las formas de intervención familiar y comunitaria, bloquear las prácticas sociales enredadas en torno a las propiedades. Con frecuencia el otorgante de los documentos renuncia 
explícitamente a disponer del bien en adelante, lo que demuestra cuando menos una peculiar concepción, hasta este período, de lo que era enajenar una posesión ${ }^{11}$. En 1261 un donante hace una concesión completa de su propiedad: «cedo todo el dominio y la posesión y por esta carta la doy (la heredad) y transfiero a vuestro poder (in potestatem uestram) y por mí y mis sucesores renuncio a todo derecho y dominio, acción y excepción y a toda ayuda de hecho y derecho» (Doc. 208). La cláusula que se consolidó en los documentos del siglo XIII fue: ut ab bac die et deinceps de iure nostro sit exempta et abrasa et in uestro dominjo sit tradita [«que desde este dia y posteriores (la heredad) sea sacada de nuestro derecho e incluida en vuestro dominio»] ${ }^{12}$.

Cinco cláusulas se consolidan de manera repetida en los documentos: que la propiedad sale del poder (juro) de los donantes y pasa al monasterio (como jur de berdade); que el precio acordado por las partes es justo, no hay engaño y realmente se paga; que el donante u otro miembro de su familia rehusa a cualquier demanda en juicio o fuera de él o a pedir que se revise el precio (cláusula de «defensa o amparo» que el monasterio impone al otorgante por la que éste tiene que avalarle con todas sus propiedades); que si lo entregado vale más, se da por la salvación de las almas (Docs. 445 y 451); en menos ocasiones, que sean anuladas todas las disposiciones anteriores que vayan contra el documento. Esta batería de cláusulas supone varias innovaciones en el período: dejar por escrito el carácter absoluto de la transferencia de la propiedad eminente, la ruptura de lazos entre el vendedor y la tierra y la limitación de los derechos de la familia, un paso más en la desarticulación del «derecho de retracto» (poder colectivo de todos los consanguíneos a reclamar con prioridad los bienes enajenados por alguno de los parientes) ${ }^{13}$.

En los cartularios del Císter llama la atención la considerable inversión en compra de tierras. En Montederramo las compras son equiparables en número a otros tipos de transacciones (de 1 a 6 por año) hasta 1270, en que ascienden a 50 . Desde 1285 se desarrolló una política de con-

"Eldora Peláez, tras vender al monasterio todo lo que tiene en la villa de Cristosende, certifica que: «no podemos vender o empeñar esta heredad, pues los hermanos (fratres) deben poseerla libre y absoluta desde este día» (Doc. 87, 1231).

12 Doc. 88, 1232. Progresivamente se fue incluyendo la renuncia al derecho de toda la progenie (Doc. 130, 1240).

${ }^{13}$ Una cláusula usual a final de siglo era: «Et rrenunciamos toda uoz et toda demanda et todo dereyto que auiamos en estes herdamentos ssobreditos, que nunca possamos dizer en juyzo nen fora de juyzo senon que e nossa uenduda et vosa conprada...» (Doc. 444, 1291; otros Docs. 77, 297). 
solidación del coto próximo al monasterio y de apropiación de parcelas en regiones de monte bajo. El Císter tuvo varias estrategias para adquirir derechos de propiedad. La más característica fue comprar propiedad dominical y a partir de los derechos políticos y de uso que ésta generaba, como los derecho comunales del monte o la posibilidad de ser vecino, ir accediendo a más propiedad ${ }^{14}$. Pero también siguieron otra vía: actuar en aquellos espacios donde habían conseguido derechos señoriales, es decir, comprar propiedad dominical donde ya tenían la jurisdicción. Se puede apreciar que donde el monasterio recibía un cillero (centro de almacenamiento de renta en especie) o derechos de cenobios anteriores en régimen exclusivo sobre una villa intentaba desarrollar un sistema de granjas; en otras palabras, reordenar la parcelación y producción. A partir de ellas, ensayaba reorganizar el régimen de propiedad y dependencia. Algunos cambios de propiedad con particulares parecen venir orientados por esta intención de tenencia absoluta en ciertas villas. En 1219 Rodrigo Pérez de Queiruganes les dio el cuarto de la ermita de San Miguel que poseía en la villa de San Martín, que ya pertenecía entera a Montederramo, a cambio de la mitad de la villa de Salceda donde el monasterio, sin embargo, compartía señorío y derechos con otros señores ${ }^{15}$. En 1225 el monasterio entregó cuatro casales a tres caballeros a cambio de toda la villa de Peredo (Doc. 69).

El sistema de adquisición de tierra por compra respondía a una pretensión - no excepcional de los cistercienses, pero sí muy característica de ellos - de clarificación de los derechos señoriales general en las pautas del comportamiento nobiliar del siglo XII como antes se ha señalado. La estrategia de compra de pequeños predios venía impuesta por los marcos fracturados de la posesión campesina y por las formas solapadas de derechos, tanto en el interior de las familias como entre los distintos señores. Cualquier mínimo avance en esta lenta labor de aglutinar propiedades colindantes supondría ventajas económicas (la posibilidad de dotar con mejor

14 Rodrigo Sánchez donó al monasterio una heredad en Seoane: «alli donde el monasterio ya hizo una cortina (pequeño predio) de la donación que le habian hecho sus hermanos» y daba licencia a Montederramo para que extendiera sus propiedades por donde quisiera (Doc. 246, 1270). En 1275 unos vendedores entregan una leira (pequeña parcela dedicada a vino) que es parte de un casal que el monasterio ya tiene a foro (Doc. 301). El 11 de mayo de 1280 Montederramo compró a Vivián Menéndez y sus cuatro hermanos y a Salvador Páez unas leiras, todas las cuales colindan con alguna otra del monasterio (Docs. 350-351).

${ }^{15}$ Doc. 63. Quizá se trata de la iglesia de San Miguel de Ribas de Sil, donada por Alfonso VII en 1152. Otro ejemplo en Doc. 265, 1272. 
infraestructura mayores superficies de cultivo o de mobilizar los recursos de unas zonas a otras) en relación a una propiedad campesina y señorial fraccionada y sobre la que pesaba toda una jerarquía de derechos ${ }^{16}$.

Sin embargo, esta política tuvo fuertes límites institucionales y culturales tanto internos a la propia organización monástica como externos a ella. La gestión directa de un dominio de grandes dimensiones bajo explotación directa habría requerido una política de elevados costes de organización de la producción en torno a núcleos centrales, de reclutamiento masivo de mano de obra, de recogida, almacenamiento y distribución de renta para abastecer el monasterio y los mercados que no se dio. Los monasterios nunca llegaron a configurarse como organizaciones netamente patrimoniales. Por el contrario, persiguieron una política de incardinación comunitaria revelándose como organizaciones capaces de redistribuir y ofrecer servicios. Por un lado, entregaron bienes a favor de quienes empleaban en su servicio de defensa militar y de articulación administrativa a cambio de fidelidad; por otro, adoptaron los mecanismos de reciprocidad, de deberes y derechos que regían las comunidades campesinas a cambio de acceder a los mecanismos de redistribución de bienes y mano de obra.

Esta cuestión refiere a una difícil pregunta sobre si la transformación en los fines se fue operando debido a que los marcos institucionales supusieron una constricción para las intenciones de los monjes o debido a que las formas de hacer y los intereses de los agentes se modelaron en un contexto económico y socio-cultural específico. Sin duda, Montederramo invirtió la mayor parte de su capital en consolidar su presencia social en el nivel local, pero este hecho no permite todavía hacer una apuesta por ninguna de las dos opciones. Menos arriesgado de postular es que en términos de gestión el resultado fue una forma mixta, como veremos seguidamente, que duró un siglo: las explotaciones vertebradas en torno a las

${ }^{16}$ Son escasos los documentos que permiten observar el alto nivel de fragmentación que tenía la propiedad campesina, si bien es una cuestión indudable cuando en ciertas transacciones se especifica en qué consistía la heredad que se traspasa. Guntroda Pérez con sus tres hijos definen la tierra que donan como: media casa en un sitio, media quintana en otro, un cuarto de un «área» y un quinto de un huerto (Doc. 132, 1240). La heredad de doña María Velasco se compone de un sexto de un área y de otro sexto en otro prado (Doc. 150, 1245). En 1282 los monjes compraron los derechos que Gómez Fernández de Seoane tenía en seis nogales, 2 castañales, todas sus moreras y una higuera grande (Doc. 371). En Nocedo y Escuadro el monasterio realizó varias compras en una negociación con diversos posesores a lo largo de todo 1274 (Docs. 281, 282, 285, 286). Estos ejemplos recuerdan que lo que parecen heredades pequeñas, pero compactas, eran en realidad derechos a partes o rentas diseminados en diversas tierras. 
granjas se dedicaron generalmente al cereal y al ganado, mientras el viñedo se explotó en régimen de arrendamiento de pequeños predios a campesinos.

\section{LAS ESTRATEGIAS ECONÓMICAS Y LAS FORMAS DE EXPLOTACIÓN}

Nada indica que Montederramo era distinto del patrón teórico de explotación del Císter, pero tampoco que fuera igual. Algunos autores han señalado que fue un centro donde la explotación indirecta por arrendamientos era más generalizada que la de tipo directo (Portela, 1981, p. 76). Las descripciones sobre las formas de explotación en el Císter remiten a un complejo problema terminológico y conceptual. El concepto de «explotación directa» es muy estrecho, si no totalmente incorrecto, para describir lo que debía de ser la explotación en el feudalismo, pues en contadas ocasiones señores e instituciones labraban directamente sus parcelas. La historia agraria va poniendo cada vez más en cuestión la existencia de dos modalidades realmente distintas de explotación o, al menos, la posibilidad heurística de los investigadores para detectar la diferencia entre ellas. En términos generales, se considera «explotación o gestión directa» en el Císter cuando una heredad se trabajaba por los monjes, por sus conversos o mediante las sernas de su campesinado solariego, pero también cuando una heredad estaba gestionada por un mayordomo u otro miembro del monasterio, que se apropiaba de parte del excedente de los campesinos que labran la tierra directamente, entregando al centro el resto. «Explotación o gestión indirecta» hace referencia a todos aquellos casos en que el monasterio arrienda un predio a un intermediario, una pareja o un miembro de la comunidad campesina, que entrega renta al monasterio y que explota y gestiona la misma con sus propios hombres.

La figura del «mayordomo», amenudo un campesino, como intermediario y colector de renta, y la frecuente ausencia de datos sobre el grado de implicación de los arrendatarios o foreros en el proceso de trabajo conlleva que la diferenciación entre ambos sistemas sea tan difícil de hacer como debía de ser para los propios contemporáneos ${ }^{17}$. Un ejemplo puede

17 En los pleitos es frecuente que los miembros de las comunidades declaren no estar seguros de a quién pertenecía una tierra o a quién se debía la renta. Si bien esto respondería en mucho casos a la resistencia pasiva de los campesinos, también refleja la indefinición objetiva de la época sobre quién era el propietario y posesor de una tierra o el beneficiario 
ilustrar estas ideas. El matrimonio de Pedro Eanes y su mujer María Pérez vendieron con reserva de usufructo dos parcelas, un bacelo y una leira (parcela generalmente dedicada a vino) en Queiruganes. Quedaron obligados a entregar el tercio de toda la producción, y «que la renta fuese exacta y se pagase en paz en la era y en el lagar al mayordomo del monasterio» (Doc. 387, 1284). El investigador considerará que la gestión es directa $o$ indirecta dependiendo de si esta pareja son los campesinos productores o si son una pareja rentista a su vez. En este caso sabemos que es la segunda opción: Pedro Eanes es un personaje relevante que tenía varias propiedades que explotaba con campesinos dependientes.

En Montederramo se intuye que se trabajaba de manera directa en las reservas y cotos con mano de obra monástica, conversa y con prestaciones de trabajo campesino ${ }^{18}$; gestión directa también en algunas de las granjas y en ciertas zonas donde los mayordomos del monasterio supervisaban la producción. La explotación indirecta se concretaba en un régimen de foros, arrendamientos y aparcería de grandes casales, a veces granjas enteras, y en parcelas de viña que proveían de renta en especie.

\subsection{La gestión directa: las granjas y los conversos}

El mundo de la explotación directa de los monasterios cistercienses es un auténtico agujero negro para los historiadores. La mayoría asume la existencia de un mundo que se intuye por los reglamentos que el Capítulo General promulgaba, pues no se sabe casi nada de una economía de la que no quedan contratos, ni descripciones, ni contabilidad; nada tampoco del régimen ganadero, que posiblemente era el centro de esta economía. Desconocemos prácticamente todo sobre las granjas, excepto las inferencias que se pueden hacer del hecho de que existan conversos que testifican, que se mencione la prestación de trabajo de los campesinos, de los mismos monjes en determinada granja o las listas de éstas. Este mundo aparece, por ejemplo, cuando el párroco de la iglesia de Santa Olalla de Escuadro renuncia a los diezmos en la villa de aquellas tierras «que los hermanos de Montederramo labran por sus manos o por sus hombres o por... (desafortunadamente rasgado) en la feligresía de la Iglesia». El tenor del

de una renta que se dividía entre varios señores distintos o que, en algunos casos, se había dejado de entregar.

${ }^{18}$ Las prestaciones de trabajo de campesinos se registran en el sur: Varonceli, Nocedo y Tamaganos. 
documento nos permite saber que la parte deteriorada está haciendo mención a los campesinos que trabajan tierras de Montederramo en régimen de aparcería con medios de producción concedidos por el monasterio:

«y si algún hombre seglar labrara por nosotros (el monasterio) en esta feligresia, pero no a nuestro costo, que dé entonces diezmo bien y cumplidamente a la parroquia, salvo si labrara en régimen de aparcería nuestra, que entonces no dé el diezmo de la parte del monasterio... pero que lo entregue bien y cumplidamente de su parte» (Doc. 476, 1294).

Evidentemente existía la explotación directa, pero era algo muy peculiar. Un documento bastante tardío (1294) ilumina alguno de los interrogantes de la especial relación entre el monasterio y las comunidades campesinas en términos de gestión. Montederramo mantiene un pleito con un particular que se apropia de una leira, es decir, de una parte de un casal, que el monasterio había entregado a otro titular. El primero, un caballero, alega que era suya y no podía ser expropiado de ella. El documento muestra varios aspectos: 1) que los vecinos de las villas y aldeas circundantes trabajaban y, en ciertos casos, moraban en un casal o leira donde el monasterio tenía una cabaña; 2) que estaban obligados a entregar la renta en otra cabaña que el monasterio tenía en Cima de Vila, donde la recogía un mayordomo de la localidad, que no parece ser un monje, y 3) que este mayordomo entregaba parte de la renta a un monje del monasterio. El mayordomo, un intermediario de estas explotaciones dominicales de Montederramo, que tenía el cargo de uno a cinco años, se quedaba con parte de la renta. Para complicar más las cosas los vecinos declaran en el pleito haber visto a este personaje labrar personalmente, durante ciertos períodos, la leira. Todo esto sitúa a este mayordomo en el mundo socioeconómico complejo de unos grupos sociales intermedios, productores y rentistas a la vez, vinculados por fidelidad a instituciones o personas y con capacidad para actuar en un nivel superior al de la aldea ${ }^{19}$.

${ }^{19}$ Los vecinos de tres poblaciones, Aguil, Preguceiro y Cerdelo, declaran lo que recuerdan sobre la leira, poniendo de manifiesto sus dudas sobre si la tierra pertenecía a Montederramo, al monasterio de Seoane de Poboeiros o al caballero que se había apoderado de ella. El hijo del mayordomo, Juan Andrés, morador de Aguil, declara haber visto labrar a Juan Sistín y llevar el pan a la cabaña de Montederramo y dar la cuarta de pan a Andrés Yánez, su padre, que la mayordomaba; añade que este Andrés Yáñez también la labró por un tiempo en nombre del monasterio y que daba la cuarta de la renta a un monje. Domingo Yáñez, morador de Cerdelo, dice haber visto a Juan Sistín morar en la cabaña de Montederramo y labrar la leira, y llevar el pan a la cabaña de Montederramo, pero 
El caso pone en evidencia los problemas para discernir entre la gestión directa e indirecta y el hecho de que al hacer microanálisis la mayoria de los casos parezcan mixtos. La hipótesis que se baraja es que en el feudalismo las instituciones extracomunitarias tenían muchas dificultades para organizar procesos de producción al margen de las villas y aldeas. Para movilizar la fuerza de trabajo necesitaban «intermediarios comunitarios». Esto implicaba no sólo un escalón añadido de extracción de renta, sino una acción económica por parte de los centros eclesiásticos dirigida a crear una malla de relaciones sociales que permitiera la conexión.

En 1295 el abad del monasterio aforó a Vasco Fernández, su mujer Marina Pérez y a su hijo un casal en Outeiro, casal que habían comprado a María Pérez de Allariz y que tuvo don García Pérez de Ambía en el que moraba Pedro Martínez. Debido a que el monasterio sustrajo al casal una parte para hacer un acuerdo con un clérigo de Escuadro, Fernando Pérez, les da también lo que el monasterio adquirió de Juan Eanes de Pesqueiras, el hijo de Sancha López de Escuadro. No interesan los personajes, por cierto todos identificables, sino la densidad de una trama de posesiones que apunta a la categoría social intermedia de estos personajes. Las condiciones del contrato exigen: que labren, reparen, den el cuarto del pan y el lino al mayordomo del monasterio, roturen, sean vasallos obedientes, den martiniega (es decir, que entreguen la renta por San Martín) y yantar (renta que substituye la obligación de dar posada y comida al abad y sus representantes cuando pasan por la villa: «y proveeréis al mayordomo, que os fuera a la era a medir el pan». Doc. 479, 1295).

Si esta pareja trabajara la tierra estaríamos ante un caso de explotación directa y de entrega de renta a un mayordomo del monasterio; si lo hiciera mediante sus campesinos dependientes y ellos fueran intermediarios rentistas a su vez, indirecta. De nuevo estamos ante la segunda opción, lo que permite plantear una interpretación más apropiada de las formas de explotación en el feudalismo. Los aparatos complejos necesitaron desarrollar dos niveles de gestión: uno, que relacionaba a los hombres del monasterio con la capa superior de la sociedad campesina local cuya concreción documental da la impresión de reflejar un universo de gestión directa de

que no sabía si daba la cuarta o cuánto. Domingo Yáñez, morador de Preguceiro, jura que don Andrés era mayordomo de Montederramo de uno a cinco años y que luego vio a fray Fernando llevar la cuarta de la leira sobredicha a Montederramo. Pedro Ruiz, morador de Aguil, alega que Juan Sistín la tuvo de uno a diez años, pero que creía que Pedro Yánez de Aguil, el polémico caballero, tenía derechos sobre ella porque la había recibido del monasterio de Seoane de Poboeiros (Doc. 475, 11 de noviembre de 1294). 
la tierra, y otro, el de éstos con los productores, que denota la existencia de un sistema de explotación indirecta. Este modelo mixto, que debía de ser predominante, explica las estrategias sociales de las instituciones eclesiásticas para enraizarse en las comunidades y va permitiendo clarificar la pregunta que se adelantaba arriba sobre la forma en que se contruyeron las intenciones de los agentes monásticos.

Un sector interesante es el de la ganadería, actividad central de la explotación directa, sujeta, sin embargo, a una fuerte negociación entre el monasterio y los caballeros y escuderos de las comunidades. El problema vuelve a ser empírico, de manera que ante la falta de expresión escrita de la economía pecuaria utilizamos como aproximación las transacciones que evidencian el interés del cenobio por acceder a los montes comunales y las zonas de pasto ${ }^{20}$.

Las regiones en las que Montederramo actuó más intensamente, desde el último cuarto del siglo xIII, fueron: Nocedo, al sur, y Escuadro-San Tirso y Cesuras-Manzaneda, al este; todas áreas de monte bajo. En 1247 el monasterio consiguió llegar a un acuerdo con un grupo de propietarios y milites, encabezados por Pedro Rodríguez «Alegre», para repartirse el monte de Covela (Doc. 159). Tuvieron que intervenir el merino del rey, el juez de la tierra, el prelado de Castrelo, el de San Veríssimo, Pedro Vivei de El Burgo, y la abadesa de Sobrado. Veinticinco personas nombradas, caballeros y monjes, «y otros muchos» se reunieron en la iglesia de El Burgo para cerrar un acuerdo; cincuenta y cuatro vecinos estuvieron presentes en el levantamiento de mojones en el mismo monte de Covela. En ese mismo año el abad pidió al rey Alfonso X exención para sus ganados si atendemos a la concesión regia al convento para que no fueran gravados por todas las vacas que se criaban cerca del monasterio (Doc. 288).

En 1275 el monasterio recibió otro importante privilegio para que poblara el monte de Los Cousos (Doc. 332). Alfonso X ordenó, a petición de su hijo Sancho IV, que todos los casales realengos que estaban yermos en las tierras de Galicia fueran dados a pobladores a foro. Juan Gato, el hombre del infante encargado de llevar a cabo la tarea, entregó al abad la totalidad del monte. La zona no estaba libre de pretendientes, ya que los numerosos caballeros y herederos (beredes, sujetos con capacidad politica) de Manzaneda y Seoane tenían múltiples derechos en él. Esto abrió

${ }^{20}$ Algunas de las menciones de parcelas compradas por el monasterio tenían derechos de pasto: en 1275 (Doc. 298) un casal en Queiruganes que compran «et os montes que pertenecen a este casal»; una viña en Os Cousos «con seu monte et con todas suas derecturas» (1275, Doc. 329; 1281, Doc. 356). 
un periodo de disputas y pactos parcamente reflejado en la documentación: cambio de propiedades en Seoane entre el monasterio y particulares, y lenta pero intensiva compra de parcelas por este último en el monte de Eirós (Docs. 312, 345 y 347). Los caballeros parecen ser un grupo en expansión, que van acaparando parte de los espacios comunales a nivel regional en aras de sus intereses ganaderos ${ }^{21}$.

En Río de Cabras, zona que lindaba con el coto monástico, el monasterio invirtió, entre 1192 y 1285, unos 555 sueldos en compras; sin embargo, no consiguió controlar un monte en el que durante un siglo los vendedores de quiñones seguirán siendo caballeros de San Tirso, Tioira y Villameá. De esta localidad tenemos un primer documento en el que cuatro personas: Juan Pérez, Pedro Pérez, María Pérez con su marido y Giralda Pérez vendieron todo lo que tenían allí (Doc. 411, 1287); un mes después lo hizo Lope Pérez, caballero de Santirso, miembro del grupo más poderoso de la villa (Doc. 412); en enero del año siguiente lo hizo Mayor Fernández, posiblemente hermana del anterior (Doc. 415). Debían de ser un linaje de caballeros con un alto índice de propiedad y cohesión. En 1192 un matrimonio, Rodrigo Sánchez y Sancha Fernández, dieron toda la propiedad que tenían y se lo reservaron a cambio de un casal, que posiblemente ya había disfrutado un pariente, Sancho Suárez, y una leira con prestaciones de trabajo (opera, Doc. 40). A su muerte se declara que el monasterio debe «recibir a todos los hombres que habitaran en dicho casal». Un siglo después los caballeros de Santirso y otros lugares, como Tioira y Villameá, siguen disfrutando de muchas propiedades. Por todo ello se puede deducir que durante este periodo de tiempo las parcelas debieron experimentar una circulación en más direcciones de las que registró el monasterio. En algunos casos el propio cenobio debió de encumbrar, mediante la compra de quiñones a muchos de estos personajes, en un proceso en el que se erigieron como negociadores frente o junto a él ${ }^{22}$.

${ }^{21}$ Doc. 419: un hombre del monasterio rotura en Villaster parte del monte de Centais y esto trae al monasterio una disputa con un caballero de Quiroga; Doc. 420: Rodrigo Velázquez, caballero de Ambía, vende a Montederramo la mitad del monte de Navallo que había comprado a los hombres de Castro. Doc. 428: Pedro López de Santirso reparte los derechos con el monasterio para que los ganados de ambas partes sean protegidos en los montes de Covela y Cabanelas.

22 En 1257 cuatro hermanas de «los López, caballeros de San Tirso»,, venden todo lo que dejó su padre en el coto de San Mamede a Río de Cabras (Doc. 186). En 1273 (Doc. 269) María y Marina González venden sus propiedades en Escuadro; en 1275 los monjes compran a María Dos Ramos (Doc. 316) y a María Yáñez (Doc. 318); en 1281 compran a Juan López, caballero de San Tirso, un cuarto del monte de Rio de Cabras 
Llegados a este punto, hay que unir este factor a la lista de consideraciones que marcaron la dinámica económica del Císter: Montederramo fue incapaz de impedir la competencia de miembros de grupos sociales intermedios dentro de su coto y evitar la ruptura de su señorío ${ }^{23}$.

Otra zona es igualmente interesante para mostrar los parámetros socio-políticos en los que se desarrollaba la acción del monasterio: el monte bajo de Escuadro. Desde principios del siglo XII se menciona la parroquia de Santa Eulalia o Santa Olalla de Escuadro, regida por el párroco don Vasco Páez. Todavía el monasterio no parece presente, aunque quizá el clérigo sea un monje del mismo y la vía de entrada. Abundan los documentos en los que unidades familiares venden sus pequeñas parcelas de tierra en lo que parece un flujo continuo de propiedad hacia Montederra$\mathrm{mo}^{24}$. De la documentación en torno a los años setenta emerge una fisonomía de Escuadro como una constelación de pequeños hábitats separados:

exigiendo ambos derechos de pasto recíprocos en las tierras del otro (Doc. 356). Su mujer vende posteriormente junto a sus hermanos por 350 sueldos. Un valioso documento de 1289 resume todos los propietarios descendientes de una familia llamada Suárez que han entrado en el monasterio o han cambiado propiedades en la misma localidad a lo largo de una centuria (1192-1289): Sancho Suárez cuando se hizo religioso; su hermana Elvira Suárez, cuando ingresó con sus hijos, y Fernando Suárez; dos Suárez más que recibieron a cambio dos casales en Manzaneda, aunque se reservaron el usufructo; Velasco Suárez a cambio de una casa en Outeiro, Menendo González todo lo que heredó de su madre; Gonzalo González y sus hermanos y hermanas, todo lo que tenían en el coto de herencia o compra; Pedro Suárez todo lo que pertenecía a su padre, y por último, Pedro Brialdi todo lo que pertenecía a su madre (Doc. 423).

${ }^{23}$ Algunas de las fracturas del coto que se observan en la segunda mitad del siglo XIII pudieron ser resultado de las reclamaciones de foreros sobre foros concedidos a perpetuidad a sus antecesores. En la villa de Lamas, coto del monasterio, un grupo de personas de Villachá de Salvador exigieron, en 1283, el traslado de una carta de «foro a perpetuidad» que el abad Gonzalo hizo, allá por 1207, a tres de sus antepasados (Doc. 379). El 22 de marzo de 1278 el monasterio arrendó una casa a una pareja en el coto de Viloxe a cambio de que le dieran toda su propiedad en Escuadro. Se comprometió a entregarles otra casa y cortina en Amoxeira, en pleno coto, cuando quedara algo vacante, sin que pagaran foro por ella (Doc. 339). En 1292 María Pérez donó el quiñón que tenía en el coto de Queixa, que se componía de sus heredades en Casdiago, Candedo y los derechos en las iglesias de Candedo y Chandreja de Queixa (Doc. 451). En 1296 Mayor Fernández de Tioira y sus parientes colaterales y vecinos, Rodrigo Menéndez y Lope Pérez, hicieron una partición de su coto de Santirso. En ella definen los derechos de pasto de su ganado frente al del monasterio (Doc. 508).

${ }^{24}$ Doc. 119, 1238; Doc. 184, 1257: Pedro Carro vende su heredad en Escuadro; Doc. 246, 1270: la madre de Juan Pérez otorga el pazo de Escuadro con sus dos hijos; Doc. 251, 1272: Martín González «Abad» vende todo lo que tiene; Doc. 252, 1272: María Fernández vende una heredad (otras en Doc. 262, en el mismo año, Doc. 280, 1274; Doc. 307, 1275, y Docs. 481 y 483 en 1295); Docs. 254 y 258, 1272: Pedro González vende con sus sobrinos; Doc. 255, 1272: la mujer de Pedro Campesino vende todo lo que tiene en la villa; Doc. 259, 1272: Marina González, hermana de Pedro González y 
el Castro, la Villa, el Monte, el Pazo, el Outeiro y el Fondo de Vila. Desde 1272 el monasterio consigue acceso a lo que parecen partes de dehesas, quiñones de la villa con derecho a monte y exigencias de trabajo comunal ${ }^{25}$. El objetivo debía de ser ganadero más que vitícola.

El trabajo prosopográfico permite advertir que estos vendedores se extienden por Costa, Santirso, Varciellas y Couzada, como atestiguan los topónimos de testigos y otorgantes y que no eran humildes campesinos, sino caballeros de Santirso o Nocedo y Reunide (Docs. 364, 406, 408, 490), que competían con el monasterio por el monte para ganado o roturación. Detrás de muchas de estas transacciones se escondía la creación de una trama de intercambio de favores, alianzas, amistades que posiblemente dé coherencia a la dinámica del «mercado de la tierra» en toda la zona. El monasterio invierte en este tipo de recursos sociales y nada indica que no participara de la concepción de redistribución y reciprocidad de la sociedad local.

Un documento de pleito entre Montederramo y el monasterio de Junqueira de Limia confirma la condición social de estos transactores, y a la vez muestra otra de las vertientes de competencia que dificultaba la acción de los monasterios: la rivalidad entre los diversos centros como señores dominicales. La sentencia concede a Junqueira de Limia entrar

María González, vende su heredad; Doc. 260, 1272: 17 personas venden sus heredades; Doc. 269, 1273: María y Marina González, hermanas de Pedro González, venden todo lo que tienen; Doc. 281, 1274: Sancha Pérez, hermana de Rodrigo Pérez e hija de Pedro Carro, vende su heredad; Doc. 282, 1274: más miembros de la familia apellidados Pérez venden todo lo que tienen; Doc. 289, 1274: Pedro González dona su parte del monte; Doc. 299, 1275: Pedro Campesino vende todo lo que tiene; Doc. 310, 1275: Domingo Pérez «Pitín» y su mujer, Mayor Suárez, venden todo lo que tienen y se reservan usufructo de por vida; Doc. 330, 1277: tres hermanos Pérez venden con Pedro Pérez «dito Charles», quizá el primogénito, todo lo que tienen; Doc. 343, 1279: Martín Abad dona todo lo que tiene de su hermano Andrés González y de sus tíos; Doc. 363, 1281: Pedro López vende por su alma todo lo que tiene; Doc. 396, 1285: la hija de Pedro Carro, Sancha Pérez vuelve a vender todo lo que tiene al monasterio; Doc. 408, 1287: Pedro Fuerte vende en nombre de su hija todo lo que tiene en Escuadro junto con tres parejas más apellidadas Velázquez, con Dominga Pérez y, de nuevo, con Marina González; Doc. 411, 1287: los hermanos Juan, Pedro y María Pérez venden sus heredadess; Docs. 476-496, 1294-1297: Gonzalo Paez dio su heredad a María Pérez de Escuadro, que vende su parte al monasterio y a Pedro Martínez de Escuadro e hijos, que también lo venden al monasterio; Doc. 490, 1296: Pedro Eanes vende todo lo que tiene de su tío Gonzalo Pérez junto con el hijo de Pedro Fuerte, Salvador Pérez; Doc. 499, 1296: otro Pedro Eanes vende al monasterio la heredad que compró de su hermana María Eanes.

${ }^{25}$ Una pareja al donar dice que su hijo «faza proe por ela ao moesteiyro ya dicto cumunalmente, assy como le fezerem doutra tanta herdade da que o moesteyro ha en Esquadro» (Doc. 363, 1281). 
y salir de los montes así como lo hacen en Avia excepto en lo que Montederramo ha comprado a los «filiis d'algo», hijosdalgo (Doc. 406, 1286). La segunda mitad de los años noventa es otro momento de concentración de ventas tras un acuerdo sobre diezmos entre el párroco de Santa Olalla, Fernando Pérez, y el monasterio ${ }^{26}$.

La salida de estos conflictos sería un resultado contingente de las fuerzas en cada momento, pero puede decirse que, en general, se concertó el reparto de los pastos y el respeto de los derechos de ambos: caballeros y entidades eclesiásticas. Sectores de caballeros estaban cediendo tierra a cambio del reconocimiento de una institución que los respaldaba frente a iguales e inferiores; Montederramo conseguía las bases sociales que posibilitaban la acción económica en la sociedad feudal.

\subsection{La gestión indirecta: los foros y arrendamientos}

Al lado de las propiedades explotadas directamente está el universo de la gestión indirecta. Si en el primero puede verse la relevancia de la puesta en marcha de redes de relaciones sociales, creemos que éstas son la auténtica clave de interpretación de las actividades en la segunda. En primer lugar, no es exacto afirmar que los monjes cistercienses gestionaron parte del dominio de forma indirecta con contratos de arrendamiento o cesión en régimen de foro. Es más apropiado decir que el monasterio accedió a gran parte de su propiedad mediante el sistema de arrendamiento de tierras a las mismas parejas que se las donaban, vendían o cambiaban.

Montederramo exigía rentas en especie junto a una renta menor en dinero que se pagaba como derechura para señalar la dependencia personal del productor, la hieradiga. Desde la década de los años setenta la renta se estandariza con las siguientes cantidades: medio o tercio del vino, tercio o cuarto del pan y hieradiga, luctuosa (pago por el acceso a una tierra tras la muerte de su anterior titular), martiniega (gallinas, huevos o frutos) y, en la zona en torno a Monterrey, además, dos servicios anuales de sernas (prestaciones de trabajo). Otras veces se añade también lino, frutos secos

${ }^{26}$ Doc. 476. Las ventas las realizaban parejas de las nuevas generaciones, hijos que confirman lo que dieron sus padres (Docs. 483, 492, 499, 505). Aparecen grupos domésticos importantes como el de Vasco Fernández y su mujer, Marina Pérez (Doc. 479), «los Velázquez» y «los González» de Costa de Sadur muy posiblemente emparentados (Docs. 481, 496, 497); Pedro Fuerte y su hijo Salvador Pérez de Castro, emparentados con «los González» (Doc. 490). Casi todas las parcelas se aforan o se reservan en usufructo a las mismas familias (Doc. 482). 
(castañas predominantemente), frutas, pescado (concretamente, pixotas, merluza) y queso. No parece haber un aumento de las rentas a lo largo del siglo, si bien se suele incrementar la prestación a pagar por los descendientes con respecto al vino (un cuarto de lo producido el padre, mientras el hijo debería pagar un tercio y la mitad el nieto) y la luctuosa. Pero las rentas raramente eran a dos voces. El arrendamiento era vitalicio, o dicho desde el punto de vista de los campesinos que solían ser los otorgantes y quienes parecen imponer la condición: la donación, venta o cambio de la tierra por el posesor se hacía con la condición de reserva de usufructo durante una vida, mientras la cual se comprometían a pagar una renta al monasterio.

Desde mediados del siglo XIII los documentos aseguran, en varias de las regiones en las que Montederramo se asentó, que la costumbre regula la cuantía de la renta que se debe, lo que indica una profunda implantación de la misma ${ }^{27}$. Desde los años ochenta, renta y servicios debidos se expresan de manera sistemática. En Trasigreja, una zona con fuerte presencia del monasterio como señor dominical y jurisdiccional, se afora a Lorenzo Pérez y su mujer un casal con la expresión «a foro de quarta, hieradiga y foros como son usados dos outros casaes da vila»; además se les pide ser vasallos y dar luctuosa como se usa en la villa (1282, Doc. 367). En Nocedo, una villa en la que el monasterio parece haber desarrollado fuertes redes de influencia, se exige servicio comunal de yantar y prestaciones de trabajo (1282-83, Docs. 384-388). En este período empiezan a ser frecuentes las ventas de predios, que se designan por su cabida en simiente - una cantidad de talegas o modios de simiente-, un indicador de superficie $^{28}$.

La economía del vino era de gestión indirecta y las condiciones se fijaban de manera contractual. Los mayordomos de cada comarca debían de realizar varias rondas para vigilar la producción y recolectar la renta de los cilleros, si atendemos a la frecuente obligación de darles yantar. En líneas generales, podría decirse sin arriesgar mucho que el monasterio fue sustituyendo una gestión fundiaria basada en las granjas por otra basada en casales arrendados, en los que los monjes mantenían su cillero. El peso creciente de la gestión indirecta, y quizá del vino --si bien esto es muy

${ }^{27}$ En Varonceli se afirma: del pan que se nos dé como es fuero (forum) en esta tierra (Doc. 175, 1255). Igualmente, en toda la Ribera del Sil la luctuosoa debía de estar ya implantada como costumbre (Doc. 320, 1275).

24 Doc. 390, 1284: «uendo dous moyos semeadura d'erdade»; Doc. 391: «vendemos I leyra... et e de $\mathrm{V}$ teegas semeadura». 
difícil de asegurar porque la naturaleza de la documentación puede estar ocultando otros sectores de explotación directa como la ganadería-, en el total de la economía del monasterio se refleja en el desarrollo de este sistema de cilleros donde se centralizó la entrega de renta ${ }^{29}$. Las granjas pasarían, en el lapso de un siglo, de ser centros productores a ser centros recolectores de renta.

Sin duda, esta evolución tenía más consecuencias que las meramente económicas: alejaba al monasterio del nivel productivo y le ponía en manos de los organizadores de la sociedad local, de ciertos grupos intermedios. Transformaba, pues, las formas de dominación además de las de explotación. Acaso por eso las cláusulas de sujeción de estos grandes aforados que pertenecían a protolinajes de caballeros, artesanos-campesinos y productores acomodados se hicieron tan explícitas: se les exigía que recibieran al abad, mayordomos y cillereros cuando fueran a la zona, que aseguraran una buena labor de la tierra, su reparación, roturación o construcción cuando fuera necesario, que pagaran el foro y la derechura, que vendieran con prioridad al monasterio y, en ningún caso, a sujetos de condición social superior y que fueran vasallos fieles y obedientes (Doc. 226, 1265; Doc. 234, 1268; Doc. 238, 1269). Como se verá posteriormente, el establecimiento de estas relaciones orientó gran parte de la acción económica de Montederramo.

La historiografía más reciente ha dejado de interpretar todo este proceso como una traición de la Regla o como un sintoma de laxitud de la Orden. La intención original de los fundadores del Císter de alejarse de las complejas redes del poder político y jurisdiccional de señores laicos y eclesiásticos no podía prescindir de la necesidad de ejercer poder político para acceder a la propiedad o posesión de la tierra. El Císter compró iglesias, derechos y villas, casales y parcelas paradójicamente para no compartir derechos con otros, pero lo hizo esgrimiendo y reforzando sus recursos políticos. La estrategia tenía que estar dirigida a entrar en la «maraña feudal» de derechos y privilegios políticos con los que alcanzar derechos de propiedad.

La conocida «relajación moral y traición a la Regla» de los cenobios cistercienses no es sino la concreción de este proceso de «envolvimiento» en una estructura de derechos compartidos de propiedad con una dinámica

${ }^{24}$ El Doc. 243 (1270) afirma que los foreros tienen que entregar el producto de sus tierras en el cillero de Trives en lugar de en la granja de Coba, que estaba arrendada. 
nétamente socio-política ${ }^{30}$. Como otros tipos de organizaciones en el feudalismo, el Císter se apoyó en la estructura organizativa y productiva de la comunidad campesina para conseguir tierras y explotar el flujo de donaciones que recibió. Esto deja en evidencia los límites organizativos y culturales de una institución que fue «dando voz», reconociendo como interlocutores, a ciertos miembros de la comunidad.

Desde los orígenes del monasterio se arrendaron tierras. En 1206 aparece el primer foro, una política de captación de los grupos sociales intermedios y de sus recursos que duraría todo el siglo. En las dos primeras décadas del siglo XIII el monasterio mantiene una carrera de arriendos situados en zonas alejadas, desde granjas hasta montes y heredades ${ }^{31}$. No da la impresión de que se tratara de la respuesta económica mediante arrendamientos de corto plazo a un problema de aumento de precios o a un problema malthusiano por la tierra. La sospecha, aunque difícil de constatar, es que en la región donde se instaló Montederramo nunca hubo una alta densidad demográfica. Las parcelas descritas no mencionan colindantes y vecinos excepto las incluidas en el perímetro de villas como Seoane, Manzaneda, El Burgo o Queiruganes. Por el contrario, parece que fuera una zona afectada por la recesión demográfica desde finales del siglo XIII.

Ciertos aspectos avalan la idea de que se dio una progresiva presión sobre la tierra desde la década de 1230. La primera luctuosa apareció

${ }^{30}$ Esta política se manifiestó en la lucha por los diezmos y el control de las parroquias - centros con derechos jurisdiccionales-, en la compra de villas con sus productores y obligaciones señoriales y en la creación de vínculos de relación personal con aquellos sujetos con poder local y con dependientes. Montederramo sostuvo pleitos con la iglesia de San Mamede de Vilachá, a la que acusó de expoliar a los foreros y serviciales del monasterio. Las sentencias del 5 de enero y del 22 de mayo de 1238 estipulan que Montederramo reciba la mitad de los diezmos de todos los foreros de la parroquia y San Mamede la otra mitad (Docs. 110, 117 y 118). El acuerdo vuelve a expresarse en 1273 con la misma sentencia para las localidades de Piñeira y de El Oliveto (Doc. 270). Tuvo también disputas con Santa María de Nocedo y San Félix de Villamarín por los diezmos de dos casales en Candeda (Sil) que finalmente se repartieron a tercios (Doc. 195, 1259) y por los derechos de sepultura y diezmos de la granja de Tamaganos (Docs. 205-206, 1260). Tendría que avanzar la coordinación organizativa de la clase dominante con la consolidación del estado moderno y la expropiación campesina para que se abriera una vía de clarificación de los derechos de propiedad y de consolidación fundiaria.

${ }^{31}$ Se arriendan las granjas de: Santa Marta, en 1214, y, de nuevo, en 1242 (Docs. 56 y 142); Pineira en 1223 (Doc. 66); Coba, que hasta ese momento estaba bajo explotación directa con el monje Velasco, se arrienda en 1242 a una pareja de señores (domnos, Doc. 140). Se renueva el arriendo en 1289 a Rodrigo Yáñez y su mujer (Doc. 432). Entre ambos debió de haber un tal Juan Martínez que plantó viñas; las viñas del monje Fernando en Requeijo se arriendan en 1245 (Doc. 151). El monte de Caba se arrienda en 1215 (Doc. 58), las heredades de Pinario en 1217 (Docs. 59 y 60). 
en 1231 (Doc. 84). En 1236 el monasterio por primera vez impuso que el convento elegía al hijo que heredaba la tierra aforada, quien debía pagar 225 sueldos como luctuosa (Doc. 104). Por las mismas fechas se exacerban los pleitos por diezmos con parroquias e iglesias. Ahora bien, no hay claros indicios de lucha por la tierra y este tipo de políticas se observan desde principios del siglo. Los documentos exigen que las tierras que el monasterio arrienda a foro no se dividan (et nunqua sit diuisa, 1223, Doc. 67), que pasen a un solo hijo (1217, Doc. 60; 1223, Doc. 66), que no se entreguen a cualquier consanguíneo (non relinquant eam alijs consanguineis nisi unj de filij) y que si hay más hijos de la pareja aforada todos ayuden a cultivar y paguen su foro conjuntamente, sin dividir la titularidad (non sint beredes in isto placito, 1217, Docs. 58-59). La imposición de la luctuosa y las disputas por diezmos fueron el resultado del avance de la capacidad jurisdiccional del monasterio y no de ciclos demográficos. Desde 1295 varias cláusulas documentales estipulan un problema precisamente por lo contrario: que las propiedades no se descuiden o se pierdan por negligencia («non perca per mao paramento»), junto a menciones de que se roture más en el monte (Docs. 479-480).

El sistema de foros y arrendamientos parece una práctica favorecida tanto por las estructuras locales como por el nivel organizativo del cenobio. Concretamente, pudo ser la forma de acceder a las parcelas dedicadas al viñedo en los valles de la ribera de los ríos. Los arrendatarios solían ser beredes que entregaban su tierra y la volvían a recibir para que la hicieran cultivar y la mantuvieran en buen estado. Generalmente tenían la obligación de roturar y construir ${ }^{32}$.

En esta época tenemos ciertos casos en los que el monasterio toma en arriendo a perpetuidad propiedades de algunos laicos. Por supuesto la transacción suele estar camuflada como una donación que hacen los laicos, pero su naturaleza es clara, porque el monasterio paga renta. En 1264 una pareja les arrendó el casal de Sas de Monte por una renta fija de 2 ó 3 modios de centeno y 8 sueldos anuales (Doc. 222). No se trataba de tierras para explotar directamente por el monasterio, sino de hacerse con propiedad dominical, situándose en ese relevante escalón intermedio de posesión. En 1266 el monasterio arrendó una heredad que tenía en Abedes a un campesino que el propio cenobio acababa de tomar en arriendo de Gonzalo López y su mujer (Docs. 228-229). El arrendador es testigo del documento anterior. Es de destacar la diferencia de renta entre las

${ }^{32} 1223$, Doc. 67. 
dos partes. El monasterio paga una modesta renta fija, el forero paga renta proporcional: un tercio de todo lo cultivado, un cuarto de lo que roture, luctuosa y dos sueldos de derechura.

\section{EL MONASTERIO COMO ACUMULADOR}

La Historia Social se ha encargado de subrayar que los monasterios eran más poderosos que las comunidades campesinas: disfrutaban de ventaja organizativa y material, más y mejores redes de relaciones sociales y un alto nivel de institucionalización. La documentación se ha interpretado bajo el prisma del interés de los cenobios por ampliar sus propiedades y estrechar la dependencia campesina. La asunción principal de este artículo es, por el contrario, que las «opciones económicas» de los monasterios estuvieron fuertemente impactadas por las estructuras y dinámicas sociales y culturales, internas y externas al cenobio. Sin embargo, Montederramo adquirió efectivamente una posición dominante ante las aldeas y villas que le rodeaban; en este sentido fue una institución eficiente de acumulación de diversos factores de la producción como se señalan a continuación.

1. El monasterio consiguió donaciones fundiarias y derechos señoriales de parte de los reyes en su propio nombre y no en el de las comunidades y sus miembros en representación de los cuales amenudo los adquiría. Estos privilegios le conferían autoridad política sobre sus campesinos. Inauguraba así una competencia desigual que sólo podía ser sostenida por determinados sujetos con cierto estatus social: nobles y agentes del rey que disfrutaban también de prerrogativas judiciales u otro tipo de privilegios sobre cotos regios preexistentes ${ }^{33}$.

2. El monasterio no era sólo objeto del favor regio. Por un lado, su relación con las comunidades implicó desde temprano un flujo continuo de donaciones. Por otro, desde la Reforma Gregoriana dos tendencias fueron progresando: la adscripción de los bienes de los monjes a los de sus instituciones y su inalienabilidad. Los monasterios devinieron colectores del patrimonio de quienes entraban a su servicio, como monjes, novicios y conversos; concretamente en Montederramo ingresaron algunos perso-

${ }^{33}$ Los primeros documentos concedidos a Montederramo por reyes y pontífices permiten ver indirectamente la formación del coto y los privilegios jurisdiccional añadidos (Docs. 1-3 y 5). Por las mismas fechas, otros nobles como Vasco Ramírez (Doc. 6) o Vasco Suárez (Doc. 7) recibieron del rey Fernando II el coto sobre varias villas con la misma inmunidad que el monasterio. 
najes con sustanciosas propiedades. El monasterio también era frecuentemente receptor último de los bienes de los familiares de los monjes, por muy patrimonialmente que éstos los gestionaran en vida ${ }^{34}$. Un monasterio era una organización peculiar, libre de los muchos problemas del ciclo familiar que aquejaban a los linajes laicos: la desmembración de la propiedad por herencia o falta de herederos y la dinámica obligadamente distributiva que tenía la casa nobiliar. El monasterio podía desarrollar estrategias de largo plazo, negociaciones intensivas sobre determinadas zonas y acumular patrimonio a largo plazo. De hecho pueden describirse ciertas tendencias ${ }^{35}$.

3. El monasterio se apoderó de gran parte de los mecanismos locales de circulación de la tierra, ya fuera porque poseían más cantidad de ella o porque ejercía su poder señorial. Su capacidad para distribuir tierra, y quizá con ella prestigio social, explica que ciertas familias compitieran por conseguir arrendar los casales del cenobio (Docs. 339, 436). El mecanismo representaba una importante vía de acumulación para el monasterio, pues las parejas que accedían a estos casales solían entregar una leira o algún predio propio que parece de propiedad alodial. Los arrendatarios mantenían ambas propiedades de por vida o a una «voz» (es decir, con derecho a designar un heredero que la disfrutaría vitaliciamente) para luego pasar las dos al monasterio, quien decidía su nuevo destino y renta (Doc. 488). Lo relevante de estas transacciones no era la acumulación de más tierra por parte del monasterio, sino el cambio en la condición social del campesinado que entraba en estas transacciones, ya que, incluso los más acomodados, aceptaban una relación personal muy estrecha con el monasterio de fidelidad y vasallaje. El campesinado, pues, accediendo a estas tierras y a esta ambivalente condición social de «amor o amistad»

${ }^{34}$ En 1252 García Fernández entró como novicio y vendió al monasterio todo lo que tenía de su madre en la villa de Feces. Se le pagó con vestidos y dinero que él mismo otorgó al vestiario, para quien era la propiedad donada (Doc. 169, 1252). En 1265 el clérigo Martín Yánez recibió todas las propiedades de su hermana María Páez por donación que hizo el marido de ésta (Doc. 224).

${ }^{35}$ En Resaio durante dos años, de 1182 a 1184, y luego durante 1238-1239, el monasterio accedió a bastante tierra (Docs. 30-35). Lo mismo en torno a Lumeares y al sur, en Tamaganos. En la Ribera del Sil, desde Cristosende a Sequer de Bueyes, hubo una gran intensidad de compras hasta la primera mitad de siglo. Después, Montederramo parece más interesado en el desarrollo del monte en torno a Escuadro: entre 1272-1275, 1286-1289 y de 1295 a finales de siglo. Esta prioridad de la ganadería quizá sea la causa de sus acciones, desde los años setenta, en Manzaneda, Seoane y Río de Cabras. En paralelo, siguió siempre actuando sobre la zona de Nocedo, Abedes y Queiruganes, posiblemente parcelas de viña $y$ cereal. 
con los monjes, estaba convirtiendo tierra alodial propia en tierra sujeta a cargas consuetudinarias. Montederramo parece tener legitimidad para modificar o conferir cierto estatus a la tierra, al otorgarle el rango de casal y granja. Por ejemplo, Pedro Rodríguez solicita, sobre las tierras que cambia y que se reserva en usufructo: que me fazades y un boo casal da mja berdade et da uossa (Docs. 382-385, 1284). Quizá algo tuvo que ver la condición de «juez» de este sujeto con el hecho de que hiciera una reclamación de carácter tan jurídico. Igualmente el monasterio definía el estatus social, al determinar las cargas y las formas de dependencia (rango de vasallo o forero o ambas) de los otorgantes o receptores. Es posible que Montederramo controlara o regulara las ventas de tierra que hacen sus «amigos» y clientes, si atendemos a ciertos casos, en que los monjes aparecen en los documentos confirmando un cambio de foro o una venta que hacen unos particulares. En 1237 Pedro Martín y su sobrina aforaron una tierra a perpetuidad a Lope Rodríguez, en la que el monje Fernando Rodríguez aparece como otorgante del documento (Doc. 107). La renta de la heredad se cobraría por los primeros, quienes tienen prioridad en la compra de la misma si el forero quisiera deshacerse de ella. Quizá el monasterio tenía la propiedad eminente de la tierra y fiscalizaba cualquier cambio de manos por debajo entre los posesores.

4. El monasterio poseía más cantidad de medios de producción que la comunidad campesina. Algunos de ellos (semillas, bueyes, arados, molinos, lagares, pesquerías) eran imprescindibles para la reproducción económica de ésta. Igualmente acumuló derechos de aprovechamiento de tierras comunales, bosques y pastos en cantidades superiores a cualquier otro particular, adquiriendo capacidad para recortar las actividades económicas de los posesores menores.

5. El monasterio no era quien movilizaba la mano de obra para explotar la tierra que compraba, arrendaba o cambiaba. Por el contrario, el posesor que entregaba la heredad solía quedar como «gestor» o como productor comprometiéndose a que la tierra fuera trabajada, los alrededores roturados, las empalizadas reparadas y las casas construidas por su familia o sus hombres dependientes. Las menciones documentales sugieren que los casales que se intercambian en estas precaria incluían campesinos ${ }^{36}$. Los protagonistas de las transacciones parecen frecuentemente de estratos

${ }^{36}$ Un ejemplo entre muchos, temprano y típico de las transacciones en que se diferencia entre los otorgantes y receptores y sus dependientes puede ser el de Fidel Vázquez, un caballero que en 1193 concede dos casales al abad, uno que trabaja Gonzalo Yáñez y el otro que lo habita Pedro Velasco (Doc. 41). 
sociales intermedios y aseguraban el trabajo de la heredad con su campesinado dependiente. A lo largo del siglo XIII el monasterio fue imponiendo la obligación de traspasar la tierra si sus posesores no podían labrarla bien. En 1232 una pareja de Lumeares, que parece pertenecer al grupo de las más humildes, alega: «que si por azar, lo que no ocurra, la dicha heredad no pudiéramos labrar por hambre, enfermedad o cualquier otro infortunio, los hermanos del monasterio la reciban y no pospongan entregarla a alguien de utilidad para el monasterio» (Docs. 88 y 188, 1258). Este tipo de acuerdo hacía recaer todos los costes sobre los arrendadores, pues las familias perdían la tierra en momentos críticos para ellas. La roturación, tan representativa de los cistercienses, era igualmente una carga sobre el productor, ya que en los contratos se indica la cantidad y el tiempo en que el campesino debía roturar ${ }^{37}$. En casi todos los casos se impone que el forero, tras haber ofrecido la tierra primero a Montederramo, venda, arriende o empeñe a quien quiera, siempre que sea de su misma condición social (ni monje, ni hidalgo), asegure a los monjes el pago de la renta y la aceptación de idénticas obligaciones. Un documento de 1233 expresa abiertamente el desinterés de Montederramo en la elección del arrendatario, pero el interés por asegurar la fuerza de trabajo: el monasterio impone a la pareja de foreros que si por ciertas necesidades no fueran capaces de cultivar la tierra buscaran un sustituto «que sin daño para nosotros cumpla plenamente su parte y foro» (Doc. 97). La gestión de la mano de obra era, pues, abandonada a las propias redes de relaciones de los miembros de las comunidades. Cincuenta años después el monasterio utiliza de forma más eficaz su capacidad política para mantener la tierra bajo su dominio señorial y, al revés, para que donde tiene propiedad dominical se entregue la tierra a hombres bajo su dominio señorial. Desde los años ochenta las cláusulas de la región de Nocedo sostienen que no se puede arrendar la tierra a quienes no son «hombres del monasterio» ${ }^{38}$. Como se ha señalado antes, es difícil discernir si la densidad demográfica era alta o baja a finales del siglo XIII. Parece lógico pensar que dependiera de los lugares, pero en términos generales da la impresión de que hubiera pocos cultivadores y terreno excedente dedicado a la ganadería. En el acuerdo de diezmos antes mencionado con la Iglesia de Vilachá se indica que Montederramo recibiera la mitad de los diezmos de todos los foreros y de aquellos que «vinieran

${ }^{37} \mathrm{La}$ exigencia más frecuente es que el campesino produjera una superficie de terreno equivalente a un modio de simiente en los dos primeros años (Doc. 298).

${ }^{38}$ Doc. 382, 1284. En 1253 el monasterio obliga a todo forero que quiera vender la heredad a hacerlo: tali bomini qui sit sub nostro dominio (Doc. 172). 
a trabajar» y que recibiera la totalidad de los diezmos si quedaran viñas libres con sus placia (Doc. 270). En 1272 Lope Rodríguez, caballero de Nocedo, entregó al monasterio una viña para que la cultivara durante cuatro años. Cuando estuviera «envinada», el miles pagaría a Montederramo la mitad del coste de la inversión y al final de los cuatro años le daría la mitad de la viña. Es obvio que el caballero no podía hacerse cargo de la leira, es decir, no podía disponer de gente que la trabajara (Doc. 266). El monte de Eirós, que era realengo yermo, se dio a Montederramo y no a pobladores para que lo poblaran y roturaran. ¿Privilegio político o incapacidad de los pobladores individuales? ${ }^{39}$.

6. Es casi imposible hacer alguna apreciación basada en la evidencia sobre el mercado del crédito, pero parece lógico que el monasterio fuera el centro de la circulación de numerario a nivel local por el simple hecho de que manejaba más y mayores cantidades en unas comunidades sin ninguna liquidez, donde las deudas se «recordaban más que se pagaban» a la espera de devolverlas por una deuda recíproca del acreedor (Doc. 389). En 1225 Montederramo pagó la hipoteca de 1.000 sueldos que pesaba sobre la villa de Peredo, que tenían tres caballeros (Doc. 69). Los escasos préstamos que aparecen suelen conllevar un avance de la propiedad del monasterio: Lope Rodríguez, caballero de Nocedo, dio todo el coto y heredad que tenía en Trez a cambio de 400 sueldos. Si conseguía redimir la propiedad, la recibiría de por vida, pero a su muerte debía pasar al monasterio de nuevo (Doc. 266). Doña Estebanita y Fernando Rodríguez «Moro» recibieron 1.000 sueldos de préstamo por todo lo que tenían en Nocedo y se lo reservaron con una renta de 300 sueldos al año durante una década. En el documento de 1275 la pareja se quedaba con el casal a perpetuidad. Nueve años más tarde vuelven a vender lo mismo, reservándose el usufructo sólo a una voz y con el compromiso de dar 100 sueldos de martiniega durante diez años (1284, Doc. 389).

El éxito o el fracaso de todas las estrategias del monasterio descritas hasta el momento estaba sujeto a una altísima contingencia definida desde por los ciclos climáticos hasta por los biológico de abades y de foreros. En años de mala cosecha el monasterio tenía toda la ventaja para negociar frente a las comunidades de su entorno; más difícil es especificar qué ocurri-

${ }^{39}$ En 1275 el monasterio compró un casal en Queiruganes que entregó a los propios otorgantes para su cultivo con la condición de que si no lo pudieran labrar debían devolverlo al abad (Doc. 298). El mismo año vuelven a acordar que si los posesores no pueden conseguir quien lo labre pierdan el casal (Doc. 304). 
ría en períodos de crecimiento económico o de recesión demográfica ${ }^{40}$. En cualquier caso, los marcos políticos en los que se producía la negociación, produción y distribución jugaban indefectiblemente a favor del monasterio. Igualmente, el monasterio actuaría preferentemente sobre elementos débiles de la comunidad como, por ejemplo, mujeres viudas o huérfanos y en momentos especiales del ciclo familiar: la muerte del padre o del titular de una tierra podía permitir comprarla, hacerse con una hipoteca o cobrar una luctuosa. Coyunturas en las que sujetaba la tierra a renta, endurecía las condiciones de las cargas o se hacía con la propiedad.

No es relevante, quizá tampoco verificable, si los «intereses» de los monasterios cistercienses fueron clarificar o no los derechos sobre sus propiedades, a pesar de las dificultades estructurales. Lo relevante es que la estrategia que utilizaron vino definida por las condiciones de tenencia compartida predominante en la sociedad feudal por la necesidad de controlar resortes sociales y políticos de poder y relaciones sociales y personales para acceder a la propiedad. Estas estrategias determinaron los fines, pues se hizo imprescindible invertir en poder jurisdiccional y redes de relaciones, redistribuir bienes y representar intereses amplios de las comunidades, y con ellos vinieron las rentas, los hombres dependientes, las iglesias y los diezmos.

\section{LOS CONTEXTOS SOCIALES E INSTITUCIONALES: REDISTRIBUCIÓN Y FORMACIÓN DE REDES SOCIALES}

Las tres formas más frecuentes de transacciones que aparecen en la documentación de Montederramo denotan los marcos sociales y culturales de las estrategias económicas del monasterio. Las que se conocen como precaria oblata, data y remuneratoria —donación, venta y cambio con reserva de usufructo e imposición de renta a los otorgantes- no eran transferencias absolutas de propiedad a favor de los cenobios. Los otorgantes quedaban con importante ascendiente sobre ellas.

En 1225 Fernando Pérez de Lampaza vende su tierra al monasterio de Montederramo por 160 sueldos con la condición de cultivarla de por

4) Hay que tener en cuenta también las variaciones regionales de dominios con posesiones en zonas geográficas tan variadas y dispersas. La localidad de Lumeares, entre 1225 y 1233, parece estar pasando una coyuntura difícil como atestiguan algunos documentos: en 1225, Fernando Pérez de Lampaza vendió todo lo que tenía «por la inmensa carencia y pobreza que yo y mis hijos e hijas (cuatro en total) sufrimos» (Doc. 70). 
vida, pagando dos sueldos y dos cuartillos de centeno como serna anual. Se le reconoce el derecho a hacer con ella lo que le plazca (Docs. 70-71). Hay muchos otros ejemplos como éste en los que es difícil saber qué tipo de derecho o de prerrogativa sobre el bien compra el monasterio. El fenómeno de la venta de tierra en la que el vendedor sigue con todas las capacidades para disponer de ella o de ventas repetidas del mismo bien es difícil de interpretar. En 1287 Pedro Fuerte vendió todo lo que tenía en Escuadro en nombre de su hija (Doc. 408). Lo hizo con tres parejas más apellidadas Velázquez y González que se deshacen de todo lo que tienen en la misma villa. Una generación después su hijo y el hijo de Marina González, una de las que vendió con Pedro Fuerte, venden de nuevo al monasterio todo lo que tienen en Escuadro (Doc. 490, 1296). Quizá eran confirmaciones de los herederos de decisiones de los padres o antecesores. Si fuera así, estas confirmaciones están hablando de la existencia de formas colectivas de tenencia de los bienes. Es interesante destacar la dimensión ritual que tienen estas confirmaciones en las que se renuevan los derechos eminentes del monasterio o la vinculación personal de las familias al monasterio. El mercado de bienes era un acto de intercambio de capacidades y derechos sobre una posesión que parece responder a una dinámica de creación y recreación de relaciones personales.

Este tipo de documentos ha sido interpretado tradicionalmente como una forma de presión del monasterio sobre los productores para apropiarse de la tierra. Sin duda esto es cierto, sin embargo no se ha reflexionado sobre la peculiaridad de la forma en que se hacía.

Si el monasterio era tan poderoso habría sido más fácil, por no decir eficaz y menos costoso, desposeer a los campesinos y organizar el proceso productivo con sus propios recursos. La razón generalmente aducida por los investigadores para explicar esto es que en el feudalismo no era sólo la tierra, sino la tierra y los hombres que la trabajaban, los objetos de la codicia de la clase dominante. El argumento vuelve a estar en una línea funcionalista al subrayar la idoneidad de las acciones de la nobleza con respecto a sus fines. Pero aceptando esta premisa se está asumiendo que la acción de la nobleza feudal tenía límites, concretamente su dificultad para poner en marcha, de manera autónoma, sistemas de producción, recogida y distribución de bienes. A partir de esto no parece excesivo aventurar que los campesinos tuvieran bastante que decir sobre la organización del trabajo y sobre las tierras que ellos y sólo ellos trabajaban.

Pero todavía se puede formular una hipótesis más atractiva, por más arriesgada. La forma en la que los monasterios se hacían con la tierra no 
era producto de una lógica maximizadora, traicionada por sus límites materiales y organizativos para movilizar su propia fuerza de trabajo. Las precaria parecen expresión de una tradición socio-cultural por la que la compra o adquisición de un bien tenía principalmente como objetivo el establecimiento, refuerzo o definición de una relación personal, el constante entrelazamiento de vínculos entre bienes y cosas, se expresara ésta como devoción religiosa, protección o servicio por dilectio o deuda (en el doble sentido de la palabra, económico y moral). La creación de redes de relación social respaldaba la posición social de colectivos o individuos y el acceso a uno $\mathrm{u}$ otro tipo de recursos.

En el mundo feudal, el «derecho» sobre los objetos se materializaba principalmente por el reconocimiento colectivo del ejercicio práctico de actuar sobre los mismos. Posiciones sociales, relaciones personales, prestigio, fama y reputación eran elementos centrales de ese reconocimiento colectivo (Mauss, 1923; Bailey, 1970; Bossy, 1983; Miller, 1990; Godelier, 1995; Smail, 1997). Los monasterios, desde este punto de vista, aparecen como potentes instituciones de penetración comunitaria, sin duda adelantados a la Casa nobiliaria y a la Monarquía, no por su poder militar o ideológico, sino por su capacidad para reconocerse mutuamente con las comunidades de su alrededor, desde caballeros a campesinos. Los monasterios consiguieron un importante grado de acción social a nivel local porque pudieron instalarse en los mecanismos de reciprocidad comunitaria, ofreciendo «servicios», generando relaciones con sujetos pertenecientes a esta sociedad: cabezas de protolinajes campesinos, familias de caballeros y escuderos, grupos de herederos, hidalgos, tenentes (Koziol, 1992; Pascua, 1999).

El marco de servicios que prestaba el monasterio a las comunidades era un marco desigual, pero no sólo a favor del monasterio, como ya se ha señalado, sino de sus «dependientes» $y$ «clientes», de sus mayores beneficiados. De aquellos que aparentemente no eran más que sumisos vasallos.

Esta relación preferencial con ciertos sectores de la comunidad campesina acentuaba la división interna dentro de la sociedad rural al dotar de recursos diferentes a ciertos miembros de la misma. Desde esta perspectiva adquiere sentido el significado de las abundantes transacciones que se hacían con el monasterio pro connitione, por reconocimiento. Algunos de los otorgantes más sujetos por cláusulas de vasallaje y fidelidad dicen explícitamente hacer su acto por los favores recibidos del monasterio: pro 
multis bonis que mibi fecistis ${ }^{41}$. Estas expresiones se han interpretado como fórmulas retóricas o manifestaciones de la subordinación ideológica campesina, pero estos «amigos» del monasterio no eran humildes campesinos. No lo era, desde luego, Arias Pérez, caballero de Caldelas, quien renunció a dos casales que ya tenía su padre en prestimonio a cambio de un casal con una bestia «por la amistad que tengo con ellos» (Doc. 171, 1252). Tampoco lo era Juan Estébanez de Nocedo, hermano de Salvador Estébanez de Monterrey, muy unido al monasterio y con múltiples arrendamientos de él, quien dice donar dos casas y dos leiras: «por mj alma et por algo que me fezeron» ${ }^{42}$. Marina Miguélez dice hacer una donación «por el mucho bien y todo lo que recibí y recibo de ese monasterio, y porque me dais mientras vivo y por la redención de mis pecados y por el alma de mi padre y madre» ${ }^{43}$. Quizá es más exacto sostener que estos individuos estaban estableciendo relaciones de reciprocidad equivalentes, que estaban hipotecando su fidelidad cayendo en dependencia con el monasterio.

¿Qué obtenían estos grupos familiares o ciertos miembros de los mismos que, en principio, no parecen sino quedar muy sujetos al monasterio? El caso de García Pérez y su mujer, Mayor Rodríguez, remite a esta ambivalente cuestión. En 1290 reciben una importante heredad en Feces de Jusaos. Tenian que entregar un cuarto de lo que produjeran y un sexto de la parte nueva que roturasen, yantar y luctuosa, además de labrar, morar, preparar y ser «vasallos sirvientes y obedientes». Se les exige que pongan en marcha las partes de la tierra que estaban abandonadas, que roturen desde el monasterio hasta las presas, que construyan casas en un solar concreto y que lo hagan morar si es que no lo quisieran habitar ellos. Los receptores se comprometen a «ser siempre deudores de amor y de ayuda a Montederramo en todos los momentos que puedan y sepan» (Doc. 435). La exigencia de ayuda podría interpretarse como una mera

${ }^{41}$ Doc. 208, 1261. Sancha Pérez da un casal por otro «por la gracia y el amor que me tenéis» (Doc. 143, 1242). Otra expresión que denota la misma vinculación especial es: remaneo in maxima pace et in magno amore («quedo en la mayor paz y amor». Doc. 100, 1234); Sancha Pérez de Escuadro «por muyto algo que ffazades Ayras, meu neto, e a mjn ffezestes muytas vezes» (1274, Doc. 281); Lope Alfonso, un personaje casado con doña Teresa, que tiene como escudero a Gonzalo Pérez y que ha recibido dos casales, alega hacerlo: «por este amor que me hacen» (1274, Doc. 273).

42 Docs. 372 y 493 : «por muyto algo et por muyta graca que rrecebo et rreceby do moesteyro ssobredito". Las leiras donadas en Foxo y Cepo serían aforadas posteriormente a su sobrino, Fernando Salvadórez (Doc. 399).

${ }^{43}$ Doc. 506 y 508: «et por muyto amor et onrra que fficeron a nosso linagen (son los caballeros de Santirso) et a nos et ffaram d'aqui adeante». 
fórmula de su subordinación al monasterio, pero más bien parece residir en ella la alianza del monasterio con estos grupos. La pareja conseguía la importante prerrogativa de explotar una considerable porción de tierra y el respaldo socio-jurídico e institucional del monasterio en su posesión y actuación frente a otros campesinos y señores. Estaba poniendo de su lado todo el entramado político, legal e institucional que representaba el cenobio.

Todavía más claro resulta el carácter de intercambio en un documento cuya primera apariencia es la de un foro a una familia humilde con pesadas cargas. Se les arrienda una heredad que se les ha comprado previamente en Forcas. Deben morarla, labrarla y prepararla, dar el cuarto del pan y la quinta de todo al mayordomo, un maravedí de martiniega, una medida de vino al mayordomo como yantar, además de que comiera «asi como for guisado», dar servicio al abad, ser vasallos y 40 sueldos de luctuosa. Pero lo que se les concede son tres casales (Espartida, Bouzas y Valle) y un privilegio muy valioso, ya que el monasterio se compromete a entregarles más casales si en toda la feligresía se quedaran otros libres y ellos pudieran hacer frente a los foros y poblarlos (Doc. 436). El monasterio está consolidando fundiariamente a cierta familia en la zona, quizá incluso no a toda la familia sino a cierta rama de la misma con una especial relación con él; una familia de «fieles vasallos».

Una aproximación al problema de la sociedad rural medieval desde la perspectiva de redes personales, parenterales y vecinales que pretenda ver los lazos entre el monasterio y sus dependientes y «clientes» demuestra la capacidad de actuación de la comunidad campesina, especialmente de algunos de sus miembros destacados. Esto nos sitúa en una interpretación distinta de la habitual en la que la negociación entre varias partes tiene algún papel en la explicación de las elecciones y posibilidades económicas de los monasterios. Al estudiar los grupos sociales llama la atención que los protagonistas de la documentación eran prelados, caballeros, pequeña nobleza rural y comunidades, que los pleitos se tenían con caballeros, con «doñas» o con clero parroquial por iglesias, villas, diezmos y rentas; que en las aldeas circundantes el espacio relacional estaba ocupado por diversos grupos en competición por el mismo. Los participantes en estos actos de intercambio de bienes, protección y fidelidad solían acceder a la gestión de grandes casales o granjas. Esto no respondía sólo a las estrategias económicas del monasterio, sino también a las del alto campesinado, campesinos-artesanos, caballeros y escuderos, beneficiarios principales del sistema de foros. 
El sistema que se impuso en Galicia durante gran parte de la Edad Media y Moderna era un sistema altamente ineficiente en términos económicos, pues consolidó una gran propiedad monástica acumuladora de renta con fines suntuarios y una pequeña propiedad campesina con cierto perfil de autosubsistencia. Fue el resultado inintencional de la negociación del monasterio con ciertos protolinajes de los colectivos de campesinos y con otras instituciones eclesiásticas en competencia por adquirir los resortes de poder con los que abrir las claves de la comunidad y acceder a la propiedad. En ese recorrido se configuró el señorío, los procesos de producción y gestión y las capacidades para la distribución y abastecimiento en Galicia.

La acumulación económica era fruto de la disposición de recursos sociales y políticos, traducidos en la sociedad feudal como relaciones sociales que permitían la acaparación de bienes y renta. Era, pues, un fenómeno no netamente, pero sí prioritariamente extraeconómico. En términos antropológicos, se diría que el monasterio rompió los patrones tradicionales de reciprocidad, al negociar aparentemente en términos de igualdad, pero con una posición superior a las comunidades. Éstas quedaron en desventaja para responder a los «servicios» -religiosos, ideológicos, de protección, crédito, concesión de tierras, acogimiento en caso de pobreza o vejez, etc.-supuestamente concedidos por el monasterio. La devolucion campesina de «estos dones» puede tener que ver con algunos de los fundamentos ideológicos que legitimaron la renta señorial.

Los monasterios del siglo XII, organizaciones feudales y patrimoniales, fueron responsables, junto con la casa del rey, de la consolidación de procesos de diferenciación social dentro de las comunidades al crear redes de relaciones personales - $y$, por tanto, de bienes- que quedaban menos expuestos a la dinámica de redistribución comunitaria campesina y a los avatares de la contingencia familiar. Esta fuerte incidencia sobre las comunidades se debe explicar desde la propia política monástica. Montederramo pudo pretender la compra y compactación de propiedades que explotarían sus monjes o mano de obra propia para colocar un producto en el mercado, pero en el proceso para conseguirlo fue definiéndose a sí mismo como actor; en él se modelaron sus intenciones.

\section{BIBLIOGRAFÍA}

Alfonso Antón, M. I. (1986): La colonización cisterciense en la Meseta del Duero. El dominio de Moreruela (siglos XII-XIV), Zamora. 
- (1990): «Poder local y diferenciación interna en las comunidades rurales gallegas», en REYNA PASTOR (coord.), Relaciones de poder de producción y de parentesco, Madrid, pp. 203-223.

- (1991): «La comunidad», en ReYNA PASTOR et alii, Poder monástico y grupos domésticos en la Galicia foral, Madrid.

- (1991): «Cistercians and feudalism», Past and Present, 133, pp. 3-30.

Álvarez Palenzuela, V. (1978): Monasterios cistercienses en Castilla (siglos XII-XII), Valladolid.

BAILEY, F. G. (1970): Gift and Poison, Londres.

Barnes, G. D. (1984): Kirkstall Abbey, 1147-1539. An historical Study, Publications of the Thoresby Society, 58/128, Leeds.

Berman, C. H. (1984): «Property Transactions and the Twelfth-century Cistercians», Proceedings of the Western Society for French History, vol. II, Kansas.

- (1986): Medieval Agriculture, the Soutbern French Countryside, and the Early Cistercians. A study of fourty-three monasteries, Philadelphia.

- (1987): Sword, Miter and Cloister: nobility and the Cburch in Burgundy, 980-1198, Nueva York, Ithaca.

BonaUdA, M. (1970): «El monasterio cisterciense de San Salvador de Oña. Economía agraria y sociedad rural», Cuadernos de Historia de España, LI-LII (1970), pp. $42-122$.

Bossy, J. (ed.) (1983): Disputes and Settlements. Law and Human Relations in the West, Cambridge.

BOUCHARD, C. B. (1986): Holy Entrepreneurs, Cistercians, knights and Economic exchange in Twelfth-century Burgundy, Londres, Cornell University Press.

BRENNER, R. (1988): «Las raíces agrarias del capitalismo europeo», en AsHTON, T. H., y PHшIP, C. H. E. (eds.), El debate Brenner, Barcelona, pp. 254-286.

- (1996): «Crecimientos y crisis de la servidumbre en la Europa medieval y moderna», Hispania, 192.

CACHARRón Mojon, A. (1988): Montederramo. El poder monacal a orillas del Mao, Orense.

Canivez, J. (ed.) (1933): Statuta Capitulorum Generalium Ordinis Cisterciensis, vol. I, Lovaina.

CHIAPPA, L. (1985): «La costruzione del paesaggio agrario padano: I cistercensi e la grangia di Valere», Studi Storici, 2, pp. 263-313.

CoCHERIL, M. (1966): Etudes sur le monachisme en Espagne et au Portugal, Lisboa.

COMBA, R. (1983): Aspects économiques de la vie des abbayes cisterciennes de l'Italie du Nord-Ouest (XIIè-XIVè siècle), Flaran, 3, Auch.

García de Cortázar, J. A. (1969): El dominio del monasterio de San Millán de la Cogolla (siglos X al XIII). Introducción a la bistoria rural de Castilla altomedieval, Salamanca.

García de Valdeavellano, L. (1993): Curso de Historia de las Instituciones españolas, Madrid.

Gautier Dalche, L. (1958): El dominio monástico de Santo Toribio de Liébana, Barcelona.

Godelier, M. (1995): «L'énigme du don», Social Anthropology, 3, pp. 95-114. HigounET, Ch. (1957): «Le premier siecle de l'économie rurale cistercienne», Istituzioni monastiche e istituzioni canonicali in Occidente, 1123-1215, Milán. 
KozıoL, G. (1992): Begging pardon and favor, Ritual and political Order in Early Medieval France, Londres.

LEKA, L. (1957): Les moines blancs. Histoire de l'Ordre cistercien, París.

McCrank, L. J. (1983): «The Cistercians of Poblet as medieval frontiersmen. An historiographic essay and case-study», Anexos de C. H. E., pp. 313-360.

MAHN, J. B. (1910); L'ordre cistercien et son gouvernement, Pisa.

Mariño VeIRAS, D. (1983): El señorio de Santa María de Meira (ss. XII.XVl). Espacio rural, régimen de propiedad y régimen de explotación en la Galicia medieval, La Coruña.

Mauss, M. (1923): «Essai sur le don. Forme et raison de l'echange dans les sociétés archaiques", Annee Sociologique.

Miller, W. I. (1990): Bloodtaking and Peacemaking: Feud, Law and Society in Saga Iceland, Chicago.

Moreta Velayos, S. (1971): El monasterio de San Pedro de Cardeña. Historia de un dominio monástico castellano (902-1338), Salamanca.

Moulin, L. (1978): La vie quotidienne des religieux au Moyen Age. Xí-Xvè siècles, París.

ORLANDIS, J. (1971): Estudios sobre instituciones monásticas medievales, Pamplona.

PASCUA EChEGARAY, E. (1999): «Vasallos y aliados con conflictos: las relaciones entre Santa María de Montederramo y la sociedad gallega del siglo XII, en Reyna PASTOR et alii, Transacciones sin Mercado: instituciones, propiedad y redes sociales en la Galicia monástica, 1200-1300, Madrid, 1999.

PÉrez de Urbel, J. (1933): Los monjes españoles en la Edad Media, 2 vols., Madrid.

Pérez Embid, J. (1986): El Císter en Castilla y León. Monacato y dominios rurales (siglos XII-XV), Salamanca.

Przzorno, A. (1987): «Politics unbound», en MAIER, C. S. (1989), Changing boundaries of the political. Essays on the evolving balance between the state and the society, public and private in Europe, Cambridge University Press, pp. 27-62.

- (1989): «Algún otro tipo de alteridad: una crítica a las teorías de la elección racional», Sistemas, 88, pp. 27-42.

Portela Silva, E. (1981): La colonización cisterciense en Galicia, Santiago de Compostela.

SMAIL, D. L. (1997): «Archivos de conocimiento y la cultura legal de la publicidad en la Marsella medieval», Hispania, 197, pp. 1049-1077.

Valous, G. (1935): Le monachisme clunisien des origines au XVè siècle, París.

WardRop, J. (1987): Fountains Abbey and Its Benefactors, 1132-1300, Michigan, Kalamazoo. 